OPEN ACCESS

Edited by:

Sandra Isabel Correia,

Universidade de Coimbra, Portugal

Reviewed by: Sebastien Christian Carpentier, Bioversity International, Belgium Renu Deswal,

University of Delhi, India

*Correspondence:

Victor Aguilar-Hernández victor.aguilar@cicy.mx orcid.org/0000-0001-8239-4047

torcid.org/0000-0001-7527-9489

Specialty section:

This article was submitted to Plant Evolution and Development,

a section of the journal

Frontiers in Plant Science

Received: 13 August 2018

Accepted: 25 October 2018

Published: 20 November 2018

Citation:

Aguilar-Hernández $V$ and Loyola-Vargas VM (2018) Advanced Proteomic Approaches to Elucidate

Somatic Embryogenesis.

Front. Plant Sci. 9:1658. doi: $10.3389 /$ fpls.2018.01658

\section{Advanced Proteomic Approaches to Elucidate Somatic Embryogenesis}

\author{
Victor Aguilar-Hernández ${ }^{1 *}$ and Víctor M. Loyola-Vargas ${ }^{2 \dagger}$ \\ ${ }^{1}$ Catedrático CONACYT, Unidad de Bioquímica y Biología Molecular de Plantas, Centro de Investigación Científica \\ de Yucatán, Mérida, Mexico, ${ }^{2}$ Unidad de Bioquímica y Biología Molecular de Plantas, Centro de Investigación Científica \\ de Yucatán, Mérida, Mexico
}

Somatic embryogenesis (SE) is a cell differentiation process by which a somatic cell changes its genetic program and develops into an embryonic cell. Investigating this process with various explant sources in vitro has allowed us to trace somatic embryo development from germination to plantlets and has led to the generation of new technologies, including genetic transformation, endangered species conservation, and synthetic seed production. A transcriptome data comparison from different stages of the developing somatic embryo has revealed a complex network controlling the somatic cell's fate, suggesting that an interconnected network acts at the protein level. Here, we discuss the current progress on SE using proteomic-based data, focusing on changing patterns of proteins during the establishment of the somatic embryo. Despite the advanced proteomic approaches available so far, deciphering how the somatic embryo is induced is still in its infancy. The new proteomics techniques that lead to the quantification of proteins with different abundances during the induction of SE are opening this area of study for the first time. These quantitative differences can elucidate the different pathways involved in SE induction. We envisage that the application of these proteomic technologies can be pivotal to identifying proteins critical to the process of SE, demonstrating the cellular localization, posttranslational modifications, and turnover protein events required to switch from a somatic cell to a somatic embryo cell and providing new insights into the molecular mechanisms underlying SE. This work will help to develop biotechnological strategies for mass production of quality crop material.

Keywords: 2D electrophoresis, differentiation, plant growth regulators, proteomics, somatic embryogenesis

\section{INTRODUCTION}

Somatic embryogenesis (SE) is of high significance to studies on plant development, particularly the changes that occur from the early to mature embryonic stages, genetic transformation of various plant species, endangered species conservation, and synthetic seed production (LoyolaVargas and Ochoa-Alejo, 2016). SE is a process by which a unique somatic cell or a cluster of cells changes, following a differentiation program, into an embryo, which is then converted by consecutive development stages into an adult plant (Yang and Zhang, 2010). It is accepted that during this process the somatic cell reverts back into an embryogenic cell (Sugimoto et al., 2011). A variety of explant tissues, which include pollen, apical meristem, root, stem, and leaf sections, as well as immature embryos, have been used to induce SE (Figure 1). 
In contrast to non-embryogenic callus (NEC) and differentiated explant (DE) that does not yield somatic embryos, the embryogenic callus (EC) and undifferentiated explant (UE) tissue contain embryogenic cells generated from the somatic cells, which are converted through a path from globular somatic embryo (GSE) to cotyledonar somatic embryo (CSE) into a mature embryo that, after a germination process, can generate a plantlet. It is accepted that a fertilized female gametophyte follows a comparable morphological path to SE, from a globular zygotic embryo (GZE) to cotyledonar zygotic embryo (CZE) (Loyola-Vargas and Ochoa-Alejo, 2016).

Somatic embryogenesis implies a switch from a somatic to an embryogenic state that is able to develop into a mature plant. These changes involve coordinated cellular, biochemical, genetic, and epigenetic changes produced by exogenous plant growth regulators (PGRs) or stress (i.e., mechanical damage or wounding), which trigger a massive expression of genes in several waves of expression. The first wave of expressing genes comprises transcription factors (TFs) such as AGL15, LEC2, LEC1, BBM, MAD-box, and WUS (Yang et al., 2012; Indoliya et al., 2016; Cao et al., 2017; Jamaluddin et al., 2017; Magnani et al., 2017). Then a second wave of transcription involves genes coding for enzymes involved in the homeostasis of auxins and cytokinins, as well as other PGRs (Ayil-Gutiérrez et al., 2013; Márquez-López et al., 2018).

More recently, attention has shifted to unveiling how the somatic cell proteome changes to promote the development of an embryogenic cell, maturation, and germination of the somatic embryo. This is not a trivial task and represents a significant research challenge, since TFs are low abundance proteins. The task is complicated by crosstalk among different metabolic pathways during the induction of SE.

In this review, we describe the currently available technologies for proteomics studies, and in turn discuss the current progress of these technologies' use for the study of SE and the changing protein patterns during the establishment of the somatic embryo.

\section{PLANT PROTEOMICS TECHNOLOGIES}

The development of different proteomics technologies has led, during the last two decades, to advances in the identification of proteins involved in the induction of SE. In brief, a proteomic pipeline consists of collecting the suitable tissue, protein homogenate preparation, proteolytic digestion, peptide separation, detection by MALDI-TOF or LC-MS/MS, and data processing. Most of the proteomic studies on SE are based on protein extracts derived from contrast morphological stages tissue, from either explant or calli to matured embryo, distinguished by a relatively easy and tractable feature such as color and size, shape, or arrange of the cells. Collectively, those studies have releveled essential and even unique proteins of somatic embryo stages. However, the precise collection of proteins triggering the conversion and fate of a somatic cell to a somatic embryo is an enigma. As it is dependent on multiple factors including different types of stress, media composition, genotype, and even the origin of a somatic cell (Quiroz-Figueroa et al., 2002; Yang and Zhang, 2010; Campos et al., 2017), likely multiple proteins could sustain the somatic to embryogenic cell conversion. Those proteins could be low abundance proteins or expressed in a spatiotemporal-dependent fashion, thus limiting their detection in complex samples presented as crude protein homogenate. The implementation of protein fractionation or enrichment before or after trypsin digestion could help to overcome the limitation by reducing the complexity of the sample for the mass spectrometry protein identification. A sample with a reduced complexity via an antibody-based enrichment for acetylated peptides from Picea asperata somatic embryos had facilitated the generation of deep acetylome that contains nearly two acetylated sites per protein identified (Xia et al., 2016).

Deciphering the interconnected proteome responsible for somatic cell switch to somatic embryo requires the determination of important protein features such as protein location, protein stability, posttranslational modifications (PTMs), and proteinprotein interactions for the proteins present in the proteome of the SE process. Besides keeping most of the proteins in the sample in solution during the preparation of protein homogenate or in step-wise isolation of specific kinds of proteins (Niu et al., 2018), the preservation of proteins and PTM is a key factor to get insights into SE proteome (Peltier et al., 2004; Xia et al., 2016; Aguilar-Hernández et al., 2017).

The protein homogenate can be subjected to a variety of proteomic approaches such as (i) two-dimensional gel electrophoresis (2DE), (ii) 2DE differential in-gel electrophoresis (2DE-DIGE), (iii) label-free proteomics, (iv) isotope-coded affinity tagging (ICAT), various isotope-labeling methods used for quantitative proteomics, including ${ }^{14} \mathrm{~N} /{ }^{15} \mathrm{~N},{ }^{16} \mathrm{O} /{ }^{18} \mathrm{O}$, or (v) iTRAQ and TMT, isobaric tags exploited for quantitative proteomics (Figure 2). Each approach has advantages and disadvantages that can be complemented by the implementation of multiple strategies in parallel. Most of the SE proteomic studies were based on 2DE and 2DE-DIGE. Overall, each of them revealed the identity of nearly 100 proteins of the 2,000 proteins that could be detected and quantified in the gels (Figure 3). 2DEDIGE eliminates much of the variation between gels observed in $2 \mathrm{DE}$ since two samples are resolved at the same time in the same gel, but requires special equipment for the image capture-laser scanning of the gels. The label-free proteomics is a gel-free approach and has positioned itself as the cheapest one proteomic approach, identifying over a thousand proteins; however, it requires intensive bioinformatics if the number of samples to compare is higher than two samples. The iTRAQand TMT-based quantitative proteomic approaches lead to the comparison of up to 10 samples at the same time; however, they are relatively expensive compared to the other quantitative proteomic methods. The ${ }^{14} \mathrm{~N} /{ }^{15} \mathrm{~N}$ approach reciprocally mixes the subject samples early, thus eliminating any further effect during protein homogenate processing, but their data analysis cannot be trivial. Recently, it has been shown that it is possible to achieve the metabolic labeling of proteins by replacing any source of nitrogen in the plant cell culture media, hydroponic solution or soil with heavy nitrogen, ${ }^{15} \mathrm{KNO}_{3}$, and ${ }^{15} \mathrm{NH}_{4}{ }^{15} \mathrm{NO}_{3}$ (Ippel et al., 2004; Kim et al., 2005; Engelsberger et al., 2006; Benschop 


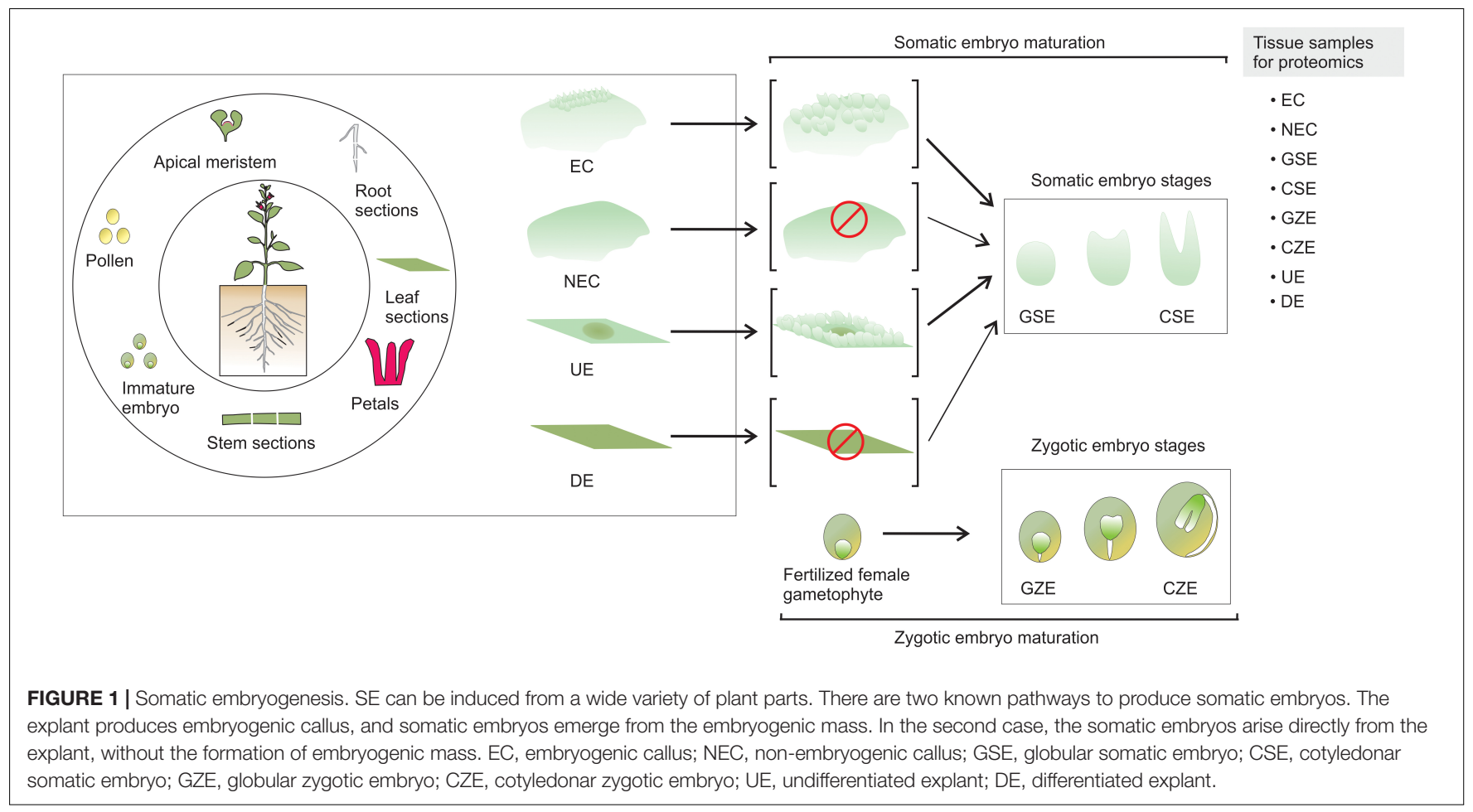

et al., 2007; Huttlin et al., 2007; Lanquar et al., 2007; Nelson et al., 2007; Bindschedler et al., 2008; Hebeler et al., 2008; Schaff et al., 2008; Laganowsky et al., 2009; Stanislas et al., 2009; Figure 2). ${ }^{15} \mathrm{~N}$ metabolic labeling proteins have displayed at least $98 \%$ and no phenotypic differences observed between metabolically labeled and unlabeled plants (Nelson et al., 2007). ${ }^{15} \mathrm{~N}$ have not been used in SE studies and its future implementation could help to get insights into quantifying proteins with a role in the SE process.

The integration of fractionation and/or type-enrichment for proteins or peptides, including resolving protein homogenate by 1D-PAGE followed by in-gel digestion and LC-MS/MS antibodybased acetylated-lysine enrichment (Zhao et al., 2015a,b; dos Santos et al., 2016; Xia et al., 2016; Alves et al., 2017), may provide new insights and in-depth proteome coverage during the induction of SE. However, few of the exquisite variety of proteomic tools have been implemented so far.

Since many of the early cell events, during the induction of SE, have been associated with nuclei and metabolic pathways compartmentalizing in multiple organelles, techniques such as Percoll, iodixanol, or sucrose gradient-dependent, and INTACT (Isolation of Nuclei Tagged in specific Cell Types)-dependent cell organelles fractionation can result in promissory for SE protein dynamic studies (Dunkley et al., 2004; Kleffmann et al., 2004; Olinares et al., 2010; Deal and Henikoff, 2011; Sikorskaite et al., 2013).

The important effect of auxin during the SE process is evident, and given that its perception and signaling are mediated by ubiquitination, a PTM with ubiquitin, there is promise in exploring ubiquitination events and their role in SE biology. PTM can be determined by an enrichment at the protein or peptide level after trypsin digestion with a protein domain, compounds (i.e., $\mathrm{TiO}_{2}$ ), and antibody-based affinity chromatography resulting in the identification of a considerable number of proteins with PTMs and the modified sites (Thingholm et al., 2006; Kim et al., 2013; Aguilar-Hernández et al., 2017). Multiple tags have been developed to perform quantitative proteomics either at the protein level such as ICAT or at the peptide level ITRAQ/TMT.

A considerable number of proteomic studies on SE have been performed, on the basis of samples from contrasting phenotypes such as EC, NEC, UE, and DE, as well as comparison of the somatic embryo stages NEC, UE, or ZE in various plant species (Table 1). A variety of plant species' proteomes have been surveyed, mainly focusing on deciphering the SE process. Crops are the dominant group in the SE proteomes reported so far. It is not a surprise that plant models with substantially advanced genetic tools such as Arabidopsis thaliana do not dominate these studies, since somatic embryo-based transformation is rare.

The comparative proteomes from contrasting phenotypes presented during SE have assumed that the later stages of SE resemble that of $\mathrm{ZE}$. Leaf explant contains different types of cells that are differentiated upon culture in vitro. All plant cells can generate calluses that are undifferentiated cell mass, and all plant cells called embryogenic cells can be dedifferentiated on the path to developing into somatic embryo. However, histologic studies of somatic embryos under development have suggested multiple origins for somatic embryos, such as proper in vitro culture, embryogenic cells derived from somatic cells by dedifferentiation or preexisting embryogenic cells, or both (Quiroz-Figueroa et al., 2002; Yang and Zhang, 2010; Campos et al., 2017). The multiple origins of somatic embryos provide a challenge not only for the over-mentioned deciphering somatic 
TABLE 1 | Embryogenic vs. non-embryogenic and non-embryogenic vs. somatic embryogenic, comparative proteomic studies from a variety of plant models.

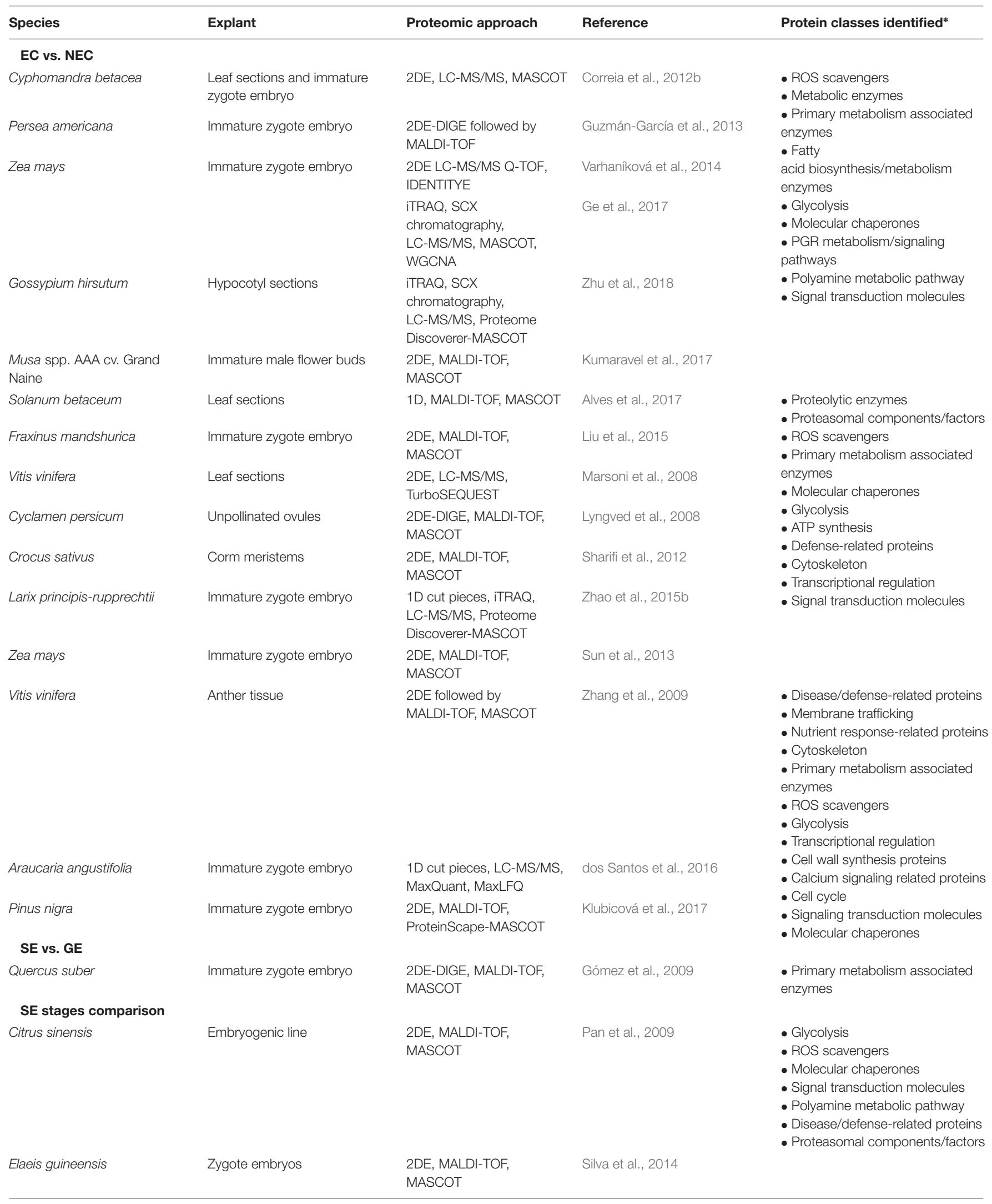


TABLE 1 | Continued

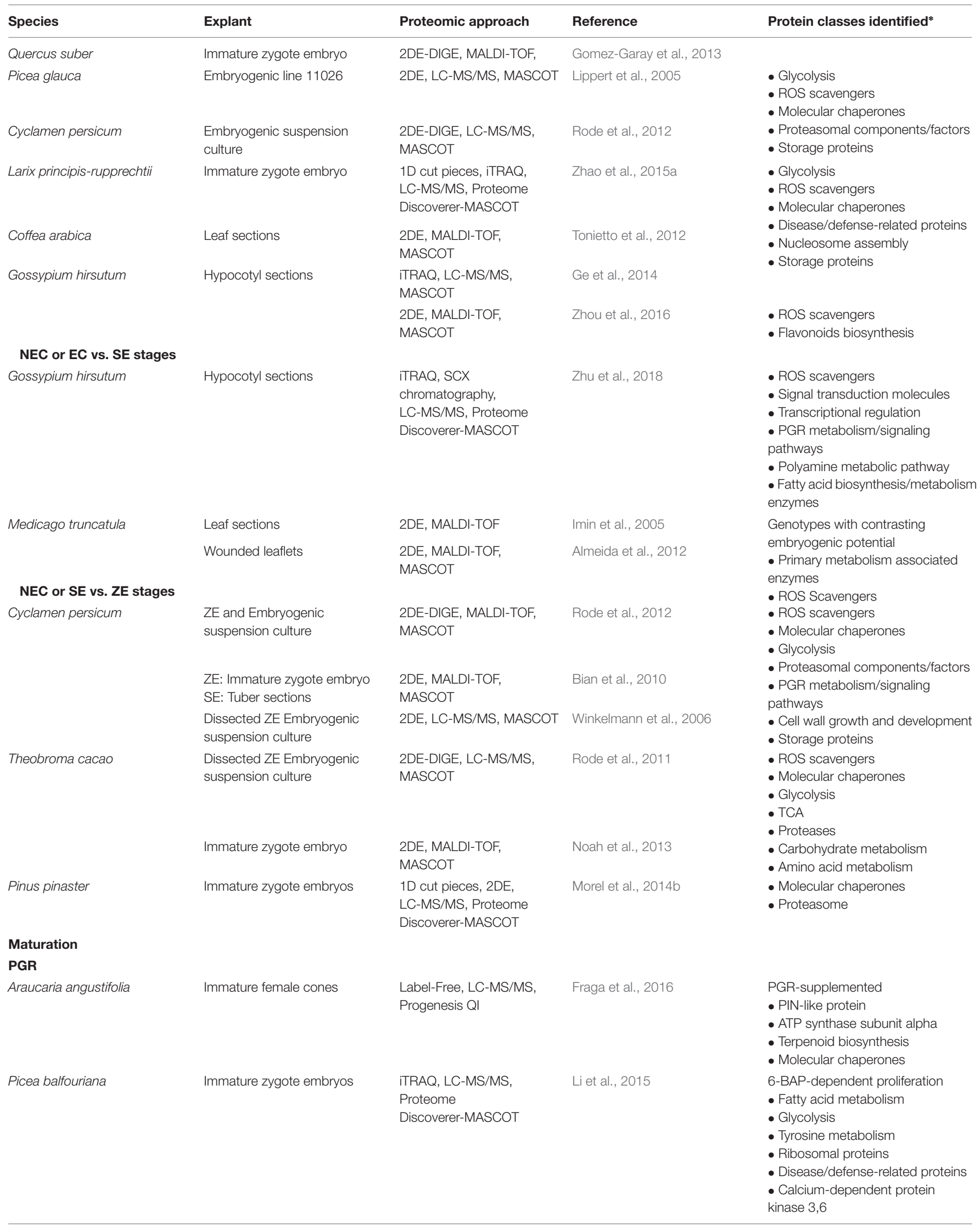


TABLE 1 | Continued

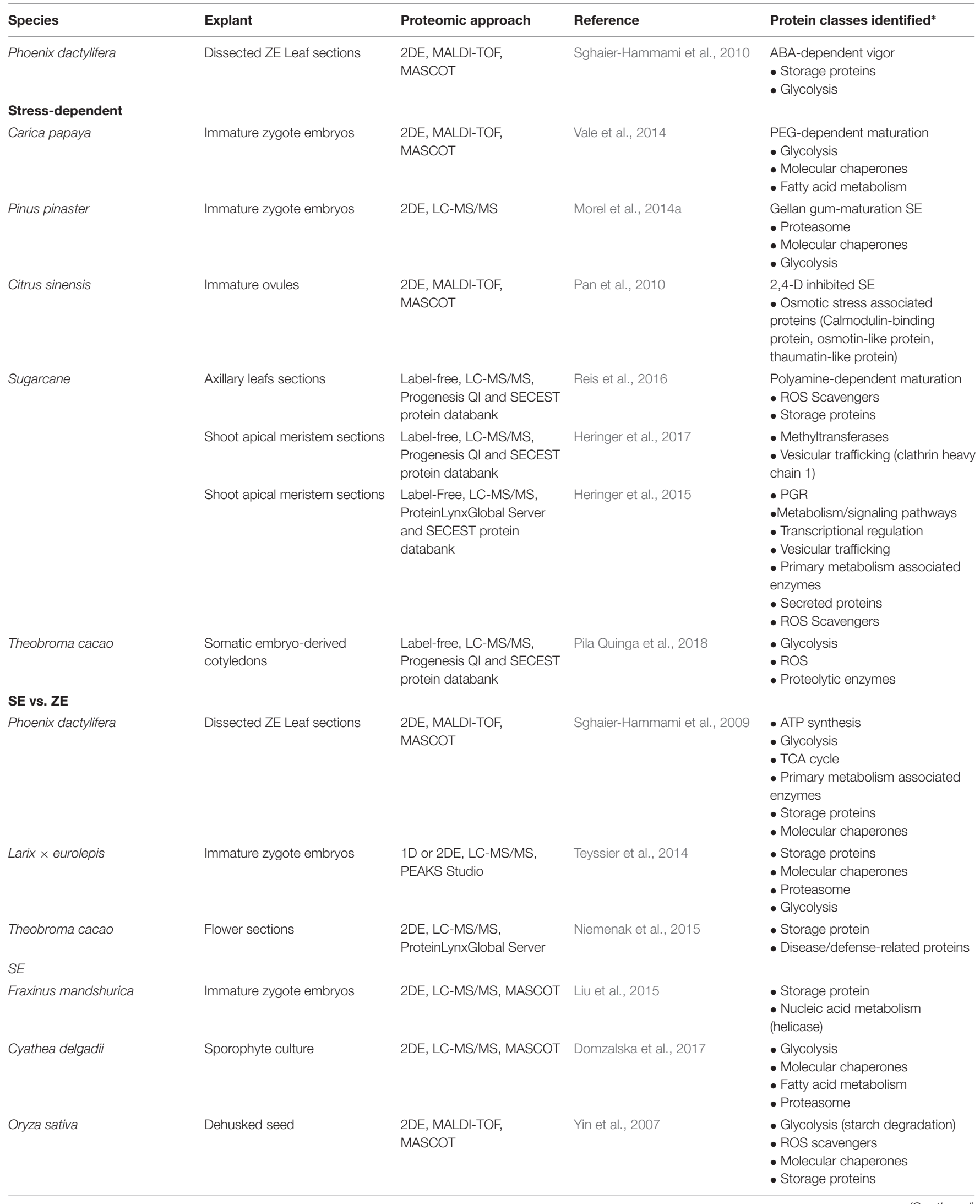


TABLE 1 | Continued

\begin{tabular}{|c|c|c|c|c|}
\hline Species & Explant & Proteomic approach & Reference & Protein classes identified* \\
\hline \multicolumn{5}{|l|}{ Germination } \\
\hline Picea asperata & Immature zygote embryos & $\begin{array}{l}\text { iTRAQ, LC-MS/MS, } \\
\text { Proteome } \\
\text { Discoverer-MASCOT } \\
\text { Lysine-acetylated peptides, } \\
\text { LC-MS/MS, MaxQuant }\end{array}$ & $\begin{array}{l}\text { Jing et al., } 2017 \\
\text { Xia et al., } 2016\end{array}$ & $\begin{array}{l}\text { Partial desiccation-treated SE } \\
\text { (Cotyledonar) } \\
\text { - ROS Sac avengers } \\
\text { - Glycolysis Fatty acid biosynthesis/ } \\
\text { metabolism enzymes } \\
\text { - Photosynthesis-related proteins } \\
\text { - Molecular chaperones } \\
\text { - Osmotic-stress related proteins } \\
\text { - Ribosome proteasome }\end{array}$ \\
\hline
\end{tabular}

* Protein classes within the groups sorted by frequency.

cell conversion to embryogenic cell but also for the detection of low abundance proteins in the complex sample from in vitro culture, since most, if not all, if not all, proteomic samples contain both types of plant cells; those cells are either undergoing the embryo formation or never give rise to an embryo.

A variety of explants have been used to study the proteome during the induction of SE, including hypocotyl and leaf sections, immature zygote embryos, unpollinated ovules, shoot meristems, $\mathrm{ZE}$ sections, and anther tissue. $2 \mathrm{DE}$ is the most exploited proteomic approach followed by 2DE-DIGE, and more recently by techniques such as label-free proteomics, iTRAQ, or antibody-based proteomics approaches (Xia et al., 2016). PGR metabolism and signaling, the ROS scavengers, primary and secondary metabolism associated enzymes, transcription regulation, signal transduction, disease/defenserelated proteins, molecular chaperones, proteolysis, and proteasomal component/factors have been identified in SE proteomes. Remarkable ubiquitin-like and ubiquitin protein modification cascade enzymes have become of substantial interest as they regulate PGR signaling in plants (Kelley, 2018).

\section{METABOLIC PGR-PRECURSORS}

Some of the proteins identified in the previous section participate in the metabolism of most, if not all, PGRs or in particular metabolic PGR-precursor synthesis pathways. For instance, cytochrome $\mathrm{P} 450$ proteins participate in the metabolism of most PGRs (Werck-Reichhart et al., 2002); phospho-2dehydro-3-deoxyheptonate aldolase 1 and 3-dehydroquinate synthase (Domzalska et al., 2017) are proteins that link the glycolysis and the pentose phosphate pathways and lead to the synthesis of phenylalanine and tryptophan as well as secondary metabolites. Indole-3-acetic acid (IAA), the main PGR with a role in the growth and development process, is synthesized mainly from tryptophan as a metabolic precursor (Zhao, 2012). Methionine synthase and S-adenosylmethionine synthetase are key enzymes in the synthesis of methionine and the metabolic precursor $S$-adenosylmethionine ( $S$-AdoMet) from aspartate, and act by feeding ethylene and polyamine production within the cell (Ravanel et al., 1998); more recently, they have been associated with the DNA methylation system
(Morel et al., 2014b; De-la-Peña et al., 2015). These are detected as more abundant at early SE in the fern Cyathea delgadii (Domzalska et al., 2017), Zea mays (Sun et al., 2013), P. glauca (Lippert et al., 2005), Citrus sinensis (Pan et al., 2009), Pinus nigra (Klubicová et al., 2017), and Persea americana (Guzmán-García et al., 2013), and more abundant in somatic embryo maturation stages in Quercus suber (GomezGaray et al., 2013), Pinus pinaster (Morel et al., 2014b), Araucaria angustifolia (Jo et al., 2014), and Larix $\times$ eurolepis (Teyssier et al., 2011, 2014). Aspartate aminotransferase, an aminotransferase enzyme that catalyzes the interconversion of aspartate and $\alpha$-ketoglutarate by transferring the amino group and yields oxaloacetate and glutamate, was detected as more abundant during the late stages of somatic embryo development in Medicago truncatula and in C. delgadii (Almeida et al., 2012; Domzalska et al., 2017). The 2,3-bisphosphoglycerateindependent phosphoglycerate is an enzyme that participates in the glycolysis pathway and was found to be more abundant in EC.

\section{PROTEINS RELATED TO SYNTHESIS AND METABOLISM OF PGRS}

Because many proteins that participate in the synthesis, degradation, transport, perception, and signaling of PGRs have been identified in many plant species, an array of biosynthesis pathways have been proposed, from inter and intracellular transport to many degradative pathways, receptors, and signaling-related proteins for PGR molecules. However, how the number of proteins in those pathways is differentially expressed has not been reported, maybe as a result of the action of either transcriptional, posttranscriptional, or posttransductional regulatory mechanisms, the natural low abundance of certain proteins (e.g., transcription factors), or organelle-dependent enzyme localization (e.g., chloroplast). One notable exception are the proteins seen in proteomic studies using iTRAQ in Gossypium hirsutum, Musa spp. AAA cv. Grand Naine, and Z. mays (Ge et al., 2017; Kumaravel et al., 2017; Zhu et al., 2018). Those proteins include indole3-pyruvate monooxygenase protein YUCCA3, an enzyme of the auxin biosynthesis, in Musa spp. AAA cv. Grand Naine that is more abundant in EC (Kumaravel et al., 2017), and 


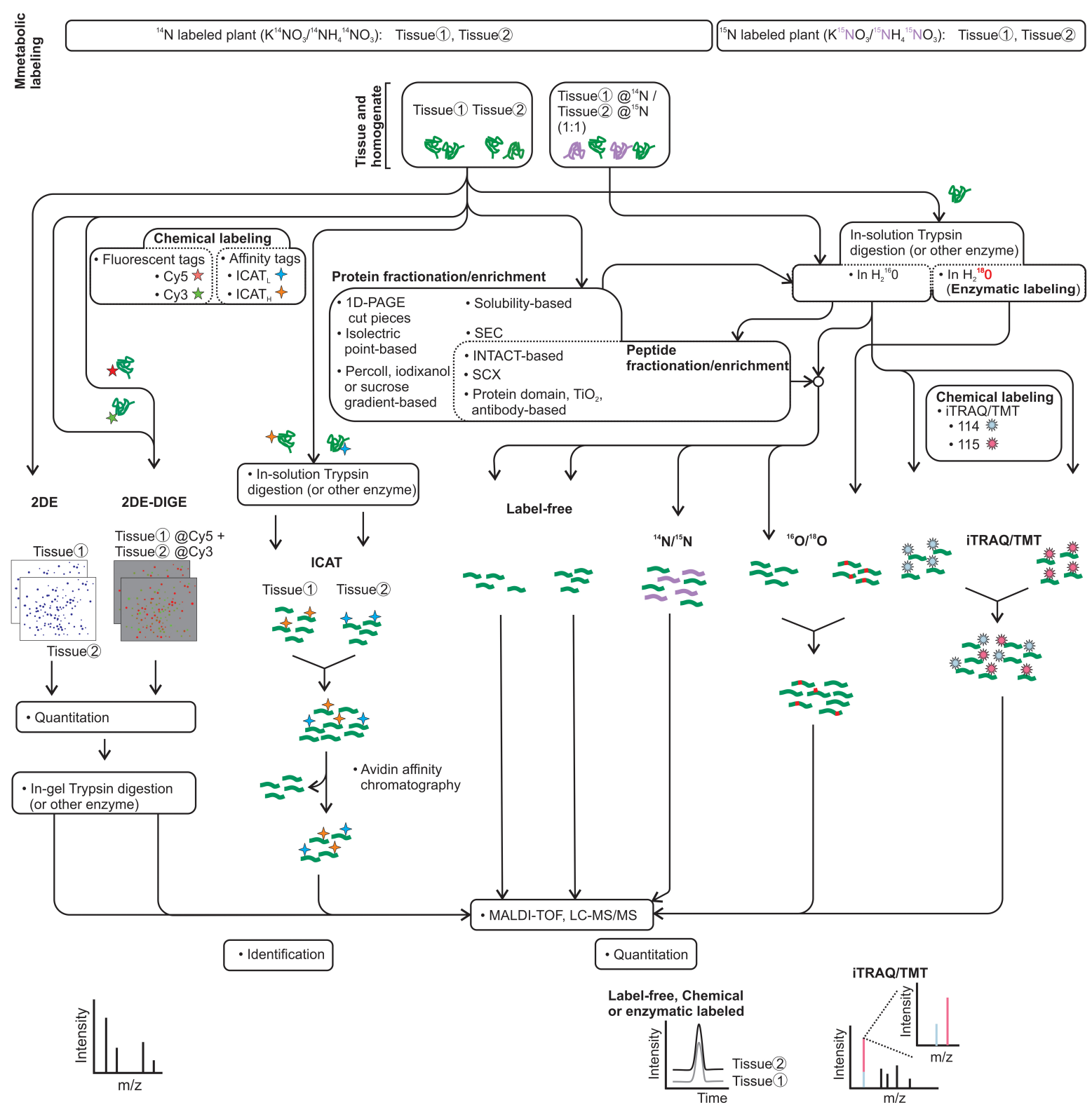

FIGURE 2 | Proteomic pipeline approaches for the SE process. 2D and 2D-DIGE that use fluorescent tags for the protein followed by MALDI-TOF or LC-MS/MS have been used extensively to contrast protein samples from the SE process. Label-free and iTRAQ, which label peptides with an isobaric tag for quantification, have been used in a few studies. The chemical labeling of proteins by ICAT reagents and peptides by TMT reagents, the metabolic labeling by ${ }^{15} \mathrm{~N}$ in vivo or by ${ }^{18} \mathrm{O}$ in vitro at the trypsin digestion, and the exploitation of protein or peptide fractionation/enrichment in the proteomic approaches may facilitate SE discoveries. Identification by MS/MS and quantification by either as a signature in extracted ion chromatogram $(X I C)$ or reporter ions are indicated.

an IAA-conjugate hydrolase GH3 that is more abundant in both EC and late SE stages in Z. mays and G. hirsutum (Ge et al., 2017; Zhu et al., 2018). GH3 collectively may result in an increase in IAA (Zhao et al., 2001). Adenylate isopentenyltransferase in Musa spp. AAA cv. Grand Naine and cytokinin trans-hydroxylase are upregulated in the EC of Z. mays (Ge et al., 2017; Kumaravel et al., 2017), cytokinin receptors CRE1 and B-ARR are more abundant in EC, and histidine phosphotransfer protein is upregulated in SE in G. hirsutum (Zhu et al., 2018), factors that are required for the cytokinin response (Mason et al., 2005). Phospholipase A1, 12-oxophytodienoic acid reductase, acylCoA oxidase, and enoyl-CoA hydratase/3-hydroxyacyl-CoA dehydrogenase are more abundant in EC at the II stage (Ge et al., 2017). These are collectively required for the jasmonic acid biosynthesis-wound-dependent pathway (Turner et al., 2002). Arogenate dehydrogenase, involved in the salicylic acid synthesis, is upregulated in the maturation stages of the EC stage in Z. mays (Ge et al., 2017). 


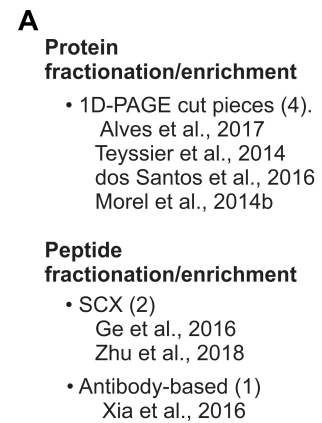

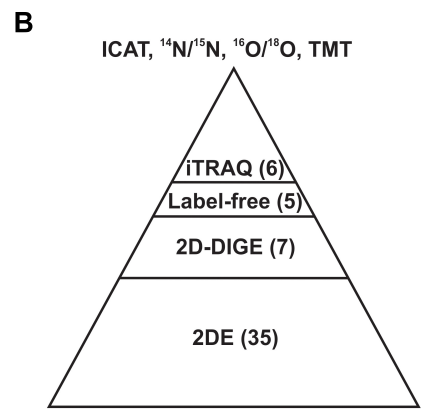

C

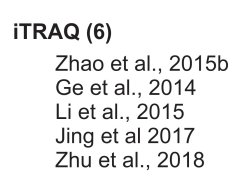

Label-free (5)

Fraga et al., 2016 Reis et al., 2016 Heringer et al., 2015 Heringer et al., 2017

Pila Quinga et al., 2018

\section{D-DIGE (7)}

Gómez et al., 2009

Lyngved et al., 2008

Rode et al., 2012

Rode et al., 2011

Guzmán-Gracía et al., 2013

2DE (35)

Lippert et al., 2005 Imin et al., 2005

Marsoni et al 2008

Winkelmann et al., 2006

Pan et al 2009

FIGURE 3 | Gel-based proteomic approaches dominate the proteomic studies on SE. (A) Protein or peptide sample fractionation/enrichment. (B) Current proteomic approaches implanted for surveying the SE proteome. (C) Top five cited studies on SE proteomics. The number within prentices indicates the number of studies compiled in this review.

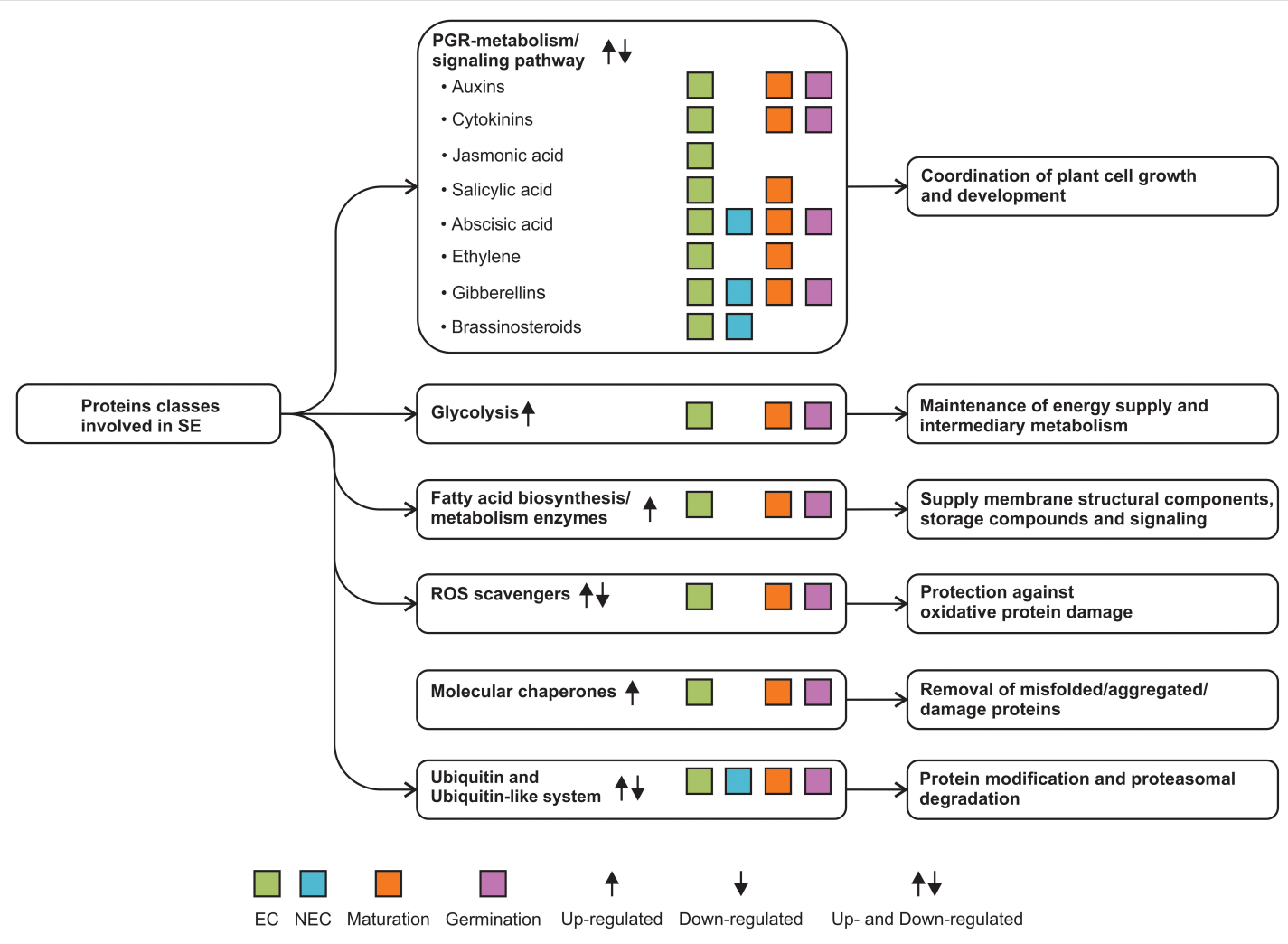

FIGURE 4 | SE proteome data reveal new protein classes involved in the SE process.

Abscisic acid plays an essential role in the accumulation of nutritive products during the development and maturation of somatic embryos (Jin et al., 2014). Pyrabactin resistance/Pyrabactin resistance-like and ABRE-binding factor transcription factor, abscisic acid signal pathway proteins from NEC to somatic embryo stages, were upregulated in EC and then downregulated in somatic embryo stages. The level of Pyrabactin resistance/Pyrabactin resistance-like showed no significant difference between NEC and EC, and was upregulated in somatic embryo stages compared with EC in G. hirsutum (Zhu et al., 2018).
The role of ethylene in embryogenic induction is complicated by its inconsistent effects on different plants and culture systems. Constitutive triple response-1 protein, which is involved in the ethylene signal pathway, was slightly downregulated in somatic embryo stages compared to EC, suggesting a possible negative role of Constitutive triple response-1 in G. hirsutum somatic embryo maturation (Zhu et al., 2018). Gibberellin-insensitive dwarf-1 protein, a gibberellin receptor, is upregulated from NEC to EC and unchanged in the somatic embryo vs. EC. DELLA is unchanged from NEC to EC and downregulated in the somatic embryo in G. hirsutum (Zhu et al., 2018). The 
cytochrome P450 734A1/PhyB-4 activation-tagged suppressor1 upregulated protein in EC in Z. mays (Ge et al., 2017) leads to the accumulation of inactive brassinolide 26-hydroxy-brassinolide (Neff et al., 1999), and is downregulated in brassinolide perception as brassinosteroid-insensitive- 1 is downregulated and BRI1-associated receptor kinase 1 is upregulated in EC and NEC and the corresponding somatic embryo stages in $Z$. mays and $G$. hirsutum (Ge et al., 2017; Zhu et al., 2018).

\section{GLYCOLYSIS-SUPPLIED ENERGY LEADS EMBRYO FORMATION}

Glycolysis, a key and ubiquitous metabolic pathway by which the plant cell converts carbohydrates to the energetic coin ATP, is a central pathway to generate energy and metabolic intermediaries that sustain the biosynthesis of intra- and extra-cellular molecules required by the cell. Proteins of the glycolysis pathway such as phosphofructokinase, fructose-1,6-biphosphate aldolase, glyceraldehyde-3-phosphate dehydrogenase, triosephosphate isomerase, phosphoglycerate mutase, 2,3-bisphosphoglycerateindependent phosphoglycerate mutase, phosphoglycerate kinase, enolase, and pyruvate decarboxylase were reported to be more abundant in the EC stage of African oil palm (Silva et al., 2014), G. hirsutum (Ge et al., 2017), maize (Sun et al., 2013; Varhaníková et al., 2014; Ge et al., 2017), saffron (Sharifi et al., 2012), Cyphomandra betacea (Correia et al., 2012b), Musa (Kumaravel et al., 2017), Vitis vinifera (Zhang et al., 2009), Larix principis-rupprechtii (Beversdorf, 1987; Zhao et al., 2015a), A. angustifolia (dos Santos et al., 2016), P. nigra (Klubicová et al., 2017), Theobroma cacao (Niemenak et al., 2015), and sugarcane (Heringer et al., 2017).

Proteomic studies employing ZE as a reference also showed that the enzymes of the glycolytic pathway are more abundant in the callus- and explant-derived SE stages from Q. suber (Gomez-Garay et al., 2013), C. delgadii (Domzalska et al., 2017), M. truncatula (Almeida et al., 2012), sweet orange (Pan et al., 2009, 2010), Coffea arabica (Tonietto et al., 2012), Cyclamen persicum (Winkelmann et al., 2006), G. hirsutum (Ge et al., 2014), Q. suber (Gomez-Garay et al., 2013), L. principis-rupprechtii (Zhao et al., 2015a), papaya (Vale et al., 2014), Larix $\times$ eurolepsis (Teyssier et al., 2011, 2014), P. glauca (Lippert et al., 2005), date palm (Sghaier-Hammami et al., 2010), C. persicum Mill (Winkelmann et al., 2006), and T. cacao (Noah et al., 2013). These findings indicate that the glycolysis pathway is used both by cells undergoing dedifferentiation and the somatic embryo, driving growth and the development process.

It is unknown how the existing cytosolic and/or chloroplastic glycolysis pathways' rate flux changes during SE to balance between energy production by the mitochondria and energy use that occurs as metabolic intermediaries are fed to the other biosynthetic pathways, such as fatty acid and secondary metabolites, operating in many cell organelles. Some proteins related to the glycolysis pathway likely regulate glycolysis by enhancing respiration or photosynthesis. Pyruvate dehydrogenase complex, dihydrolipoyl acetyltransferase, and dihydrolipoyl dehydrogenase are accepted as potential control points for metabolism, moderating the balance between catabolism and anabolism. This makes sense, given their connection with other metabolic pathways, and the fact that it is tightly regulated by multiple factors, including light, product inhibition, organelle-specific mechanism, and phosphorylation/dephosphorylation (Luethy et al., 2001; Tovar-Méndez et al., 2003).

Chloroplast and mitochondrial $\alpha$ and $\beta$ isoforms of pyruvate dehydrogenase E1 from C. persicum (Lyngved et al., 2008) and C. delgadii (Domzalska et al., 2017) were found to be upregulated in EC as well in somatic embryo maturation. Research indicates the chloroplast dihydrolipoyl dehydrogenase 1 is upregulated from C. delgadii (Domzalska et al., 2017), Larix $\times$ eurolepis (Teyssier et al., 2014), and P. nigra (Klubicová et al., 2017). Furthermore, pyruvate dehydrogenase was downregulated in ZE from C. persicum (Mwangi et al., 2013). Whether the regulation of pyruvate dehydrogenase protein by phosphorylation is occurring during the SE process or if this protein is regulated by unknown mechanisms is still not known.

\section{FATTY ACIDS}

Acetyl-CoA derived from glycolysis by the action of the pyruvate dehydrogenase complex functions as a link between carbon metabolism and fatty acid biosynthesis. As a substrate of the acetyl-CoA carboxylase (ACC), acetyl-CoA is used to produce malonyl-CoA, then utilized as a malonyl group donor, which is transferred to the acyl-carrier protein (ACP) by a malonylCoA:acyl carrier protein, malonyltransferase. The fatty acid biosynthesis pathway involves a multienzymatic cascade by the action of 3-ketoacyl-ACP synthase (KAS) isoforms I, III, and II, 3ketoacyl-ACP reductase, hydroxyacyl-ACP dehydratase (HAD), and enoyl-ACP reductase (ENR) that utilizes acetyl-CoA as the starting unit and malonyl-CoA as a two-carbon unit donor to yield an 18-carbon fatty acid attached to ACP. Then, the saturated or desaturated fatty acids released from the fatty acid machinery by an ACP desaturase (SAD) and/or acyl-ACP thioesterase can either enter the galactolipid, sulfolipid, and/or phospholipid synthesis pathways or be exported from the plastid to the ER, where they ultimately coalesce in oil droplets of fat to wax and/or cutin synthesis (Mou et al., 2000; White et al., 2005; Pidkowich et al., 2007; Li-Beisson et al., 2013).

The proteome from early SE of C. delgadii (Domzalska et al., 2017) and maturation stages of the somatic embryo from P. pinaster (Morel et al., 2014a) exhibited ACC as an upregulated protein; an accumulation of this protein has also been seen in biochemical assays as an increase in the activity of the ACC enzyme in EC and somatic embryos from carrot (Wurtele and Nikolau, 1992). Malonyltransferase, as well as KAS I, II, and II, was upregulated in both EC and somatic embryos from G. hirsutum (Zhu et al., 2018). Enoyl-ACP reductase was upregulated in the maturation of polyethylene glycol (PEG)dependent somatic embryo from C. papaya (Vale et al., 2014) and even in the ZE from C. persicum (Mwangi et al., 2013). Additionally, SAD was detected in EC from C. persicum (Lyngved et al., 2008). 
The upregulation of proteins of the core fatty acid biosynthesis pathway in early somatic embryo formation and somatic embryo maturation suggests that this central pathway is active and might support downstream metabolic pathways required during SE. Lipid transfer proteins, a collection of extracellular proteins with a secretory peptide, are thought to participate in the movement of surface lipids required for the formation of wax and cutin (Wirtz, 1991; Li-Beisson et al., 2013). A lipid transfer protein was upregulated in CSE from G. hirsutum (Ge et al., 2014) and phospholipid transfer protein 1 was upregulated during somatic embryo maturation of sugarcane embryos in a light qualitydependent fashion (meaning embryo maturation under white light plus medium blue, red, and far-red) (Heringer et al., 2017), suggesting that surface lipids are an essential factor in embryo maturation.

To utilize fatty acid as a source of energy or to generate metabolic precursors, plants have exploited an array of lipases and the $\beta$-oxidation pathway. Remarkably, SE process proteomic studies so far have found Gdsl esterases/lipases to be upregulated in EC from A. angustifolia (dos Santos et al., 2016), in proembryonic masses from in $P$. americana (Guzmán-García et al., 2013), in the SE cotyledonar stage of G. hirsutum (Ge et al., 2014), and in PEG-dependent SE maturation in C. papaya (Vale et al., 2014). Nevertheless, the physiological role of Gdsl esterases/lipases in SE is still mostly undetermined. Numerous members of the Gdsl esterases/lipases have been well documented in plants, and their participation in signal transduction during plant development, the synthesis of secondary metabolites, and plant defense response have been well studied, including Arabidopsis Gdsl lipase 2 (Lee et al., 2009), which is very attractive for studying them during the induction of SE. Core proteins of $\beta$-oxidation process such as CoA oxidase (ACX) in EC from Z. maize (Ge et al., 2017), and the multifunctional protein in both EC from $Z$. maize and SE maturation of Larix $\times$ eurolepsis were found to be upregulated (Teyssier et al., 2014; Ge et al., 2017). The upregulation of core proteins in a wide range of conserved metabolic pathways such as fatty acid biosynthesis and $\beta$-oxidation process suggests a tight regulation between those processes, particularly in the EC, but also at early stages of somatic embryo development, as well as in somatic embryo maturation.

\section{ROS AND COUNTERPART ROS SCAVENGERS DURING SOMATIC EMBRYOGENESIS}

Reactive oxygen species [ROS, reviewed in Das and Roychoudhury (2014)] are side products of the aerobic metabolism in an oxygen-evolving photosynthetic organism (Halliwell, 2006). ROS can be free radicals such as $\mathrm{O}^{-}$and $\mathrm{OH}$, as well as non-radicals such as $\mathrm{H}_{2} \mathrm{O}_{2}$ and ${ }^{1} \mathrm{O}_{2}$. As counteractive mechanisms, plants have adopted a sophisticated battery of ROS scavengers to reduce the harmful effect of ROS in the cell. It is accepted that ROS production by a stress stimuli might be required to induce cell dedifferentiation, triggered by the mechanical damage of an explant and/or stimulated by a variety of molecules such as the auxin analog 2,4-dichlorophenoxyacetic acid (2,4-D) and PEG (Fehér, 2015). Proteins related to detoxification include superoxide dismutase in $P$. Americana (Guzmán-García et al., 2013), Q. suber (Gómez et al., 2009), V. vinifera (Zhang et al., 2009), and L. principis-rupprechtii (Zhao et al., 2015a); ascorbate peroxidase in Z. mays (Sun et al., 2013); glutathione-S-transferase in C. sativus (Sharifi et al., 2012), V. vinifera (Marsoni et al., 2008), and M. truncatula (Imin et al., 2005); catalase (CAT) in C. persicum (Rode et al., 2012) and L. principis-rupprechtii (Zhao et al., 2015b); and monodehydroascorbate reductase and dehydroascorbate reductase in A. angustifolia (dos Santos et al., 2016). All of these enzymes are upregulated in EC. Therefore, an active counteraction to ROS by ROS scavengers is an important factor in the fate of EC.

In contrast to EC, early somatic embryo initiation displayed downregulation of some proteins related to detoxification, such as Mn superoxide dismutase in G. hirsutum (Ge et al., 2014); CAT in C. delgadii (Domzalska et al., 2017), and Q. suber (GomezGaray et al., 2013); ascorbate peroxidase in Q. suber (GomezGaray et al., 2013) and G. hirsutum (Ge et al., 2014); and guaiacol peroxidase (GPX) in G. hirsutum (Ge et al., 2014), although this enzyme is upregulated across PGR- or stress-dependent somatic embryo maturation (Teyssier et al., 2011; Morel et al., 2014a; Vale et al., 2014; Li et al., 2015). Notably, at the cotyledonar somatic embryo stage, GPX is even more abundant at the somatic embryo stage (Rode et al., 2012) than its ZE counterpart (Gomez-Garay et al., 2013; Mwangi et al., 2013; Morel et al., 2014b; Silva et al., 2014; Niemenak et al., 2015).

Moreover, the upregulation of CAT has been detected in the partial desiccation treatment of germinated somatic embryo of $P$. asperata (Jing et al., 2017). Accurate quantification by iTRAQ has allowed the unraveling of two CAT3 and one CAT1 upregulated proteins in GSE and CSE compared with their proembryonic masses, and one CAT1 is upregulated in GSE followed by downregulation in the CSE in L. principisrupprechtii (Zhao et al., 2015a). The presence of multiple protein isoforms might be an indication that posttranscriptional regulation mechanisms are essential during the induction of SE.

\section{MOLECULAR CHAPERONES}

The myriad of newly synthesized proteins, as well as folded proteins that can either develop into the unfolded form or coalesce into aggregates upon stress exposure, that require a folding process to develop into biologically active proteins is significant (Boston et al., 1996). Therefore, the active folding process that is mainly determined in the primary sequence and enhanced by the action of foldases or molecular chaperones is crucial for the proper function of the cell. The foldase enzymes, such as protein disulfide isomerase that catalyzes the arrangement of disulfide bonds and peptidyl prolyl isomerase (PPI) that switches the conformation of the peptide bond prior to a proline residue, participate in refolding processes. In addition to their refolding role in the cell, chaperones such as heat shock proteins (HSP) also have a role in preserving proteins in 
an unfolded form that is suitable for translocation of proteins across membranes, evading the formation of protein aggregates, enabling disassembly of aggregated proteins (Ellis and Van der Vies, 1991), and, as recent research shows, participate in degradation of protein complexes and even cell organelles under stress conditions (Marshall and Vierstra, 2018).

Peptidyl prolyl isomerase was found to be upregulated in EC (Zhao et al., 2015b), downregulated during proembryogenic masses' GSE, then upregulated in CSE in L. principis-rupprechtii (Zhao et al., 2015a). During the maturation of the somatic embryo, PPI was detected as unique for a somatic embryo derived from EC and upregulated in a mutual white/blue/red/farred-dependent maturation of sugarcane (Heringer et al., 2015, 2017), upregulated in GSE of Larix $\times$ eurolepsis (Teyssier et al., 2014), the CSE stage of the somatic embryo in C. persicum Mill (Rode et al., 2012), and shown to be more abundant in somatic embryo maturation than ZE maturation of T. cacao (Niemenak et al., 2015).

In addition, FKBP-type PPI was found to be upregulated in the CSE of G. hirsutum (Ge et al., 2014) and in somatic embryos undergoing maturation in M. truncatula (Almeida et al., 2012). A cyclophilin-type PPI was detected to be upregulated in GSE and CSE of C. arabica (Tonietto et al., 2012). As cyclophilins are encoded by multiple genes (Romano et al., 2004), and might be a part of a conserved evolutionary mechanism that assists in the expression of the auxin-regulated genes (Lavy and Estelle, 2016), further experimentation regarding cyclophilin's role during SE is needed. Both of the ATP-dependent chaperones HSP70 and HSP100 were detected in somatic embryos, in contrast to the CplA/HSP100 that was upregulated in EC of Z. mays (Varhaníková et al., 2014).

Variants of the HSP70 were detected extensively among the SE plant models. HSP70 was found to be uniquely expressed in EC from Musa spp. AAA cv. Grand Naine (Kumaravel et al., 2017) and rice (Yin et al., 2007). Moreover, HSP70 is upregulated in the callus of C. persicum (Rode et al., 2012), and in the EC of C. betacea (Correia et al., 2012a), V. vinifera (Marsoni et al., 2008), and Crocus sativus (Sharifi et al., 2012). Variants of HSP are upregulated in callus- and explant-derived somatic embryo stages that include GSE in P. glauca (Lippert et al., 2005) and C. delgadii (Domzalska et al., 2017), and in polyamine-dependent maturation of somatic embryo from sugarcane (Reis et al., 2016) and in PEG-dependent somatic embryo maturation in C. papaya (Vale et al., 2014). Similar expression patterns, upregulated between proembryogenic masses and GSE stages and followed by downregulation during CSE in L. principis-rupprechtii, have been reported (Zhao et al., 2015a,b).

HSP70 was also detected in ZE of T. cacao (Niemenak et al., 2015), and was more abundant in somatic embryos than in the ZE counterpart in C. persicum (Winkelmann et al., 2006). Findings in Phoenix dactylifera that displayed HSP70 as more abundant in ZE than in SE (Sghaier-Hammami et al., 2009) suggest that both up and downregulation of HSP70s are occurring during SE. Indeed, HSP70 belongs to multiple gene families. HSP90 was upregulated during the induction of SE in Elaeis guineensis (Silva et al., 2014) and in C. delgadii (Domzalska et al., 2017), downregulated during SE in samples containing somatic embryo stages from globular to cotyledonar in G. hirsutum (Zhu et al., 2018), and upregulated in Larix $\times$ eurolepsis under gellan gum-dependent maturation at the SEG (Teyssier et al., 2011) and cotyledonar stages (Teyssier et al., 2014). Bip/GRP78 were found to be upregulated between proembryogenic masses and GSE stages followed by downregulation during CSE in L. principis-rupprechtii (Zhao et al., 2015a), and in PEG-dependent maturation in C. papaya (Vale et al., 2014).

The chaperonin HSP60 was detected as downregulated in the EC of C. persicum (Lyngved et al., 2008), upregulated in the cotyledonar stage of both somatic embryo and ZE-derived embryos from G. hirsutum (Ge et al., 2014) and the cotyledonar stage of C. persicum (Mwangi et al., 2013). The small HSP class I chloroplast HSP 25.3 was found to be uniquely expressed in EC from Musa spp. AAA cv. Grand Naine (Kumaravel et al., 2017), and the cytosolic HSP type 2 was upregulated at the induction of SE in C. delgadii (Domzalska et al., 2017). During the induction of SE in $P$. pinaster, the cytosolic HSP18.2 was upregulated in $\mathrm{CSE}$ and the counterpart in the ZE-derived embryo, and the class II HSP17.6 was upregulated during somatic embryo maturation (Morel et al., 2014b).

\section{PROTEOLYTIC ENZYMES AND THE UBIQUITIN PROTEASOME SYSTEM}

Biochemical analyses of the proteolytic activity reveal that serine proteases, aspartic proteases, and metalloproteases are dominant in EC, whereas serine proteases dominate NEC in Solanum betaceum (Alves et al., 2017). Leucine aminopeptidase has been found to be unique to PEG-dependent somatic embryo maturation of C. papaya (Vale et al., 2014). Metalloprotease m41 and aspartyl protease have been detected as upregulated in EC of A. angustifolia and in the blue/red light-dependent somatic embryo maturation in sugarcane (dos Santos et al., 2016; Heringer et al., 2017), downregulated at somatic embryo maturation in cacao (Pila Quinga et al., 2018) and at the torpedo stage of SE compared to the torpedo stage of ZE (Noah et al., 2013; Niemenak et al., 2015). The cysteine protease displays a similar pattern: this enzyme is upregulated at the early stages of SE in P. glauca (Lippert et al., 2005) and downregulated during the somatic embryo maturation in cacao (Pila Quinga et al., 2018).

Intriguingly, evidence of accumulation of cystatin, a cysteine protease inhibitor, in the EC of saffron (Sharifi et al., 2012) and Vigna unguiculata (Nogueira et al., 2007) has been reported. Therefore, protease action is very dynamic and linked to the counteractive action of proteolytic inhibitors during the SE process.

Ubiquitin (Ub) and proteins related to $\mathrm{Ub}$, also called ubiquitin-like proteins, are attached to substrates via a cascade of related enzymes $\mathrm{E} 1 \rightarrow \mathrm{E} 2 \rightarrow \mathrm{E} 3$; then these modified proteins face a selective and non-selective degradation into the $26 \mathrm{~S}$ proteasome. Also, ubiquitination directs protein trafficking or modified protein properties as well as location in the cell (Vierstra, 2009; Marshall and Vierstra, 2018). 
$\mathrm{Ub}$ and poly-Ub 10 have been detected in embryogenic cell suspension of cowpea (Nogueira et al., 2007) and in explants undergoing SE in cassava (Baba et al., 2008); both are upregulated in GSE and CSE in L. principis-rupprechtii (Zhao et al., 2015b). Poly-Ub 11 was upregulated 61-fold in somatic embryo polyamine-dependent maturation (Reis et al., 2016). Ub fused to the ribosomal protein S27a in embryogenic suspension culture of V. unguiculata (Nogueira et al., 2007), in the EC and NEC stages of $Z$. mays (Ge et al., 2017), and during the induction of SE in cassava (Almeida et al., 2012). Poly-Ub 11 is upregulated in the embryogenic callus of C. persicum (Rode et al., 2012). Interestingly, the constitutive overexpression of S27a has shown a correlation with the increase of proliferation of undifferentiated cells and arrest of the shoot and leaf development (Hanania et al., 2009).

Small ubiquitin-related modifier (SUMO), an ubiquitin-like protein, has been found to be upregulated in GSE and CSE in L. principis-rupprechtii (Zhao et al., 2015a), and during PGRor PEG-dependent somatic embryo maturation (Vale et al., 2014; Fraga et al., 2016). Interestingly, the disruption of the two encoded SUMO genes in A. thaliana results in an early embryo lethal phenotype (Saracco et al., 2007). Ubiquitinconjugated enzymes (called E2/UBC) have been identified; UBC5 in leaf-derived somatic embryos of $C$. delgadii (Domzalska et al., 2017), Ub carrier protein E235 in somatic embryos of cacao (Niemenak et al., 2015), the E2 variant 1D/MMS2 during somatic embryo maturation, UBC32 during polyaminedependent somatic embryo maturation, and UBC9, which is downregulated in blue/red light-dependent somatic embryo maturation of sugarcane (Reis et al., 2016; Heringer et al., 2017). SUMO-activating enzyme subunit 2-like/SAE2 is upregulated during the maturation of somatic embryo of $P$. pinaster (Morel et al., 2014a) and in the blue/red light-dependent maturation of somatic embryo of sugarcane (Heringer et al., 2017).

E3 ubiquitin ligase is responsible for recognizing ubiquitination targets across the cell. In the EC of sugarcane and A. angustifolia, the RING-type E3 ubiquitin ligases BRCA1 and ORTH2 were identified, respectively (Heringer et al., 2015; dos Santos et al., 2016), while during somatic embryo maturation the RING-type ubiquitin ligase ARI2 is upregulated in A. angustifolia (Fraga et al., 2016).

The components of the SCF-(Skp1-CULLIN1-F-box)-type Ub ligase such as an F-box protein and a SKP1 protein were found to be upregulated during maturation in either $C$. sinensis or A. angustifolia (Pan et al., 2010; Fraga et al., 2016).

The proteasome that executes the degradation of ubiquitinated proteins comprises the catalytic core particle (CP), where proteolysis occurs, and two terminal regulatory particles (RP) that serve as the switch for the activation of the proteasome. CP proteins such as PAA1 were detected in an embryogenic cell suspension of $V$. unguiculata and found to be upregulated in the EC of $V$. vinifera and from CSE to the mature somatic embryo of Q. suber (Nogueira et al., 2007; Zhang et al., 2009; Gomez-Garay et al., 2013). PBA1 was detected in embryogenic suspension cultures of $V$. unguiculata and found to be upregulated in the somatic embryo of $P$. pinaster and in Q. suber from CSE to the mature somatic embryo (Gomez-Garay
TABLE 2 | Promising proteomic technologies for SE.

\begin{tabular}{ll}
\hline Proteomic technology & Somatic embryogenesis \\
\hline Histone PTM modifications & Epigenetics \\
PTM modifications: & Signal transduction \\
phosphoproteomics, & \\
ubiquitin proteomics, etc. & \\
Protein-DNA and & Transcriptional regulation \\
RNA-protein interactions & \\
Protein-protein interactome & Signal transduction \\
Protein-ligand interactome & Signal transduction \\
Protein complex-RNA & Posttransductional \\
& regulation \\
Organelle proteomics & Metabolism \\
INTACT cell type-specific & Cell type-specific \\
\hline
\end{tabular}

et al., 2013; Morel et al., 2014b). PBF1 is upregulated in somatic embryo gellan gum-dependent maturation of $P$. pinaster (Morel et al., 2014a,b).

Regulatory particles proteins, such as RPT5, are upregulated in the EC of C. persicum, Musa spp. AAA cv. Grand Naine, saffron and H99 inbred maize (Lyngved et al., 2008; Sharifi et al., 2012; Sun et al., 2013; Kumaravel et al., 2017), and have been identified in the somatic embryo and $\mathrm{ZE}$ of $C$. persicum (Bian et al., 2010). Additionally, RPT1 is upregulated during the SE of C. delgadii (Domzalska et al., 2017). RPT3 is found in the early development stages of SE in C. persicum (Rode et al., 2012), and RPT2 is found in the somatic embryo gellan gumdependent maturation of $P$. pinaster (Morel et al., 2014a). RPN12 is upregulated during somatic embryo maturation in C. delgadii and NEC of Musa spp. AAA cv. Grand Naine (Domzalska et al., 2017; Kumaravel et al., 2017). Interestingly, the disruption of $R P N 12 A$ in $A$. thaliana results in a decrease in its sensitivity to cytokinins and 2,4-D; given the upregulation of cytokinininducible genes such as CYCD3 and NAI1 in rpt12a seeds, the authors suggest that a feedback-inhibitory mechanism is present (Smalle et al., 2002). Recently, it was shown that this inhibition requires the response regulator B-type ARR5 that is accumulated in the rpn12a seeds (Jasmina et al., 2013). RPN9 is upregulated in blue/red light-dependent maturation of the somatic embryo of sugarcane (Heringer et al., 2017). Collectively, the differential expression of $\mathrm{Ub}$, Ub-like modifiers, components of the $\mathrm{Ub}$ cascade, and $26 \mathrm{~S}$ proteasome suggests the participation of Ubdependent protein degradation during the SE process.

\section{CONCLUSION AND PERSPECTIVES}

Proteomic approaches are emerging as a powerful tool to define the somatic embryo's changes through the early stages of its development and during the maturation and germination of somatic embryos. As proteomic studies in other systems, SE proteomics studies need to cope with factors such as protein abundance and sample complexity that limit to performer dipper proteome analysis. Protein concentration into the cell is a key factor related to protein abundance and sample complexity, which also limits a dipper proteome analysis of the SE process since somatic embryo can come from multiple origins and the 
abundance of proteins with a role in somatic embryo formation could be spatiotemporal-dependent. Most current studies have examined the early stages of somatic embryo development using EC and NEC as the model, along with PGR-, PEG, and blue/red light-dependent somatic embryo maturation. Proteomics is helping to decipher the signal that switches the genetic program from a somatic cell to an embryogenic cell and its later conversion to a mature embryo. Glycolysis, fatty acid biosynthesis, ROS scavengers, and molecular chaperones are the most reiterative protein classes identified by proteomes of SE. However, there are still a large number of important metabolic pathways to study, such as ATP metabolism and the mechanism of signal transduction for auxins and cytokinins. No less critical could be to explore protein modifications via ubiquitin and ubiquitin-like and their connection with molecular chaperones protein class to control the abundance of key proteins for SE, mostly unknown so far (Figure 4).

Finally, it is essential to turn to the study of the organelle proteome during SE. The isolation of the nucleus, mitochondria, vacuoles, and other organelles can lead to the discovery of key proteins involved in the process of induction of SE. It is

\section{REFERENCES}

Aguilar-Hernández, V., Kim, D. Y., Stankey, R. J., Scalf, M., Smith, L. M., and Vierstra, R. D. (2017). Mass spectrometric analyses reveal a central role for ubiquitylation in remodeling the Arabidopsis proteome during photomorphogenesis. Mol. Plant 10, 846-865. doi: 10.1016/j.molp.2017.04.008

Almeida, A. M., Parreira, J. R., Santos, R., Duque, A. S., Francisco, R., Tomé, D. F. A., et al. (2012). A proteomics study of the induction of somatic embryogenesis in Medicago truncatula using 2DE and MALDI-TOF/TOF. Physiol. Plant. 146, 236-249. doi: 10.1111/j.1399-3054.2012.01633.x

Alves, A., Caeiro, A., Correia, S. I., Veríssimo, P., and Canhoto, J. (2017). Establishment and biochemical characterization of tamarillo (Solanum betaceum Cav.) embryogenic cell suspension cultures. In Vitro Cell. Dev. Biol. Plant 53, 606-618. doi: 10.1007/s11627-017-9864-z

Ayil-Gutiérrez, B. A., Galaz-Ávalos, R. M., Peña-Cabrera, E., and Loyola-Vargas, V. M. (2013). Dynamics of the concentration of IAA and some of its conjugates during the induction of somatic embryogenesis in Coffea canephora. Plant Signal. Behav. 8:e26998. doi: 10.4161/psb.26998

Baba, A. I., Nogueira, F. C. S., Pinheiro, C. B., Brasil, J. N., Jereissati, E. S., Juca, T. L., et al. (2008). Proteome analysis of secondary somatic embryogenesis in cassava (Manihot esculenta). Plant Sci. 175, 717-723. doi: 10.1016/j.plantsci.2008.07.014

Benschop, J. J., Mohammed, S., O’Flaherty, M., Heck, A. J. R., Slijper, M., and Menke, F. L. H. (2007). Quantitative phosphoproteomics of early elicitor signaling in Arabidopsis. Mol. Cell. Prot. 6, 1198-1214. doi: 10.1074/mcp. M600429-MCP200

Beversdorf, W. D. (1987). "Application of plant tissue and cell culture to field crops improvement, the up-and down-side," in Plant Biology Vol. 3. Plant Tissue and Cell Culture, eds C. E. Green, D. A. Somers, W. P. Hackett, and D. D. Biesboer (New York, NY: Alan R. Liss, Co.), 359-365.

Bian, F., Zheng, C., Qu, F., Gong, X., and You, C. (2010). Proteomic analysis of somatic embryogenesis in Cyclamen persicum mill. Plant Mol. Biol. Rep. 28, 22-31. doi: 10.1007/s11105-009-0104-5

Bindschedler, L. V., Palmblad, M., and Cramer, R. (2008). Hydroponic isotope labelling of entire plants (HILEP) for quantitative plant proteomics; an oxidative stress case study. Phytochemistry 69, 1962-1972. doi: 10.1016/j. phytochem.2008.04.007

Boston, R. S., Viitanen, P. V., and Vierling, E. (1996). Molecular chaperones and protein folding in plants. Plant Mol. Biol. 32, 191-222. doi: 10.1007/978-94009-0353-1_9 of particular interest to use the new quantitative proteomic techniques, since in many cases it is not the absence/presence of a protein that determines the physiological effect, but its amount. It is also essential to determine the patterns of modification in the proteins, i.e., acetylation, phosphorylation, ubiquitination, and many other protein modifications. All of these techniques (Table 2), together with the transcriptomics studies, will achieve new insights into the understanding of the dynamic and complex interconnection of events that take place during the induction of somatic embryogenesis.

\section{AUTHOR CONTRIBUTIONS}

All authors developed the idea and drafted the manuscript.

\section{FUNDING}

This work was supported by the National Council of Science and Technology (FS-1515, FORDECyT 296195, INFR-2015-01255045, and INFR-2017-01-280898 to VL-V).

Campos, N. A., Panis, B., and Carpentier, S. C. (2017). Somatic embryogenesis in coffee: the evolution of biotechnology and the integration of omics technologies offer great opportunities. Front. Plant Sci. 8:1460. doi: 10.3389/fpls.2017. 01460

Cao, A., Zheng, Y., Yu, Y., Wang, X., Shao, D., Sun, J., et al. (2017). Comparative transcriptome analysis of SE initial dedifferentiation in cotton of different SE capability. Sci. Rep. 7:8583. doi: 10.1038/s41598-017-08763-8

Correia, S., Cunha, A., Salgueiro, L., and Canhoto, J. (2012a). Somatic embryogenesis in tamarillo (Cyphomandra betacea): approaches to increase efficiency of embryo formation and plant development. Plant Cell Tissue Org. 109, 143-152. doi: 10.1007/s11240-011-0082-9

Correia, S., Vinhas, R., Manadas, B., Lourenço, A. S., Veríssimo, P., and Canhoto, J. M. (2012b). Comparative proteomic analysis of auxin-induced embryogenic and nonembryogenic tissues of the Solanaceous tree Cyphomandra betacea (Tamarillo). J. Proteome Res. 11, 1666-1675. doi: 10.1021/pr200856w

Das, K., and Roychoudhury, A. (2014). Reactive oxygen species (ROS) and response of antioxidants as ROS-scavengers during environmental stress in plants. Front. Environ. Sci. 2:53. doi: 10.3389/fenvs.2014.00053

Deal, R. B., and Henikoff, S. (2011). The INTACT method for cell type-specific gene expression and chromatin profiling in Arabidopsis thaliana. Nat. Prot. 6:56. doi: $10.1038 /$ nprot.2010.175

De-la-Peña, C., Nic-Can, G. I., Galaz-Ávalos, R. M., Avilez-Montalvo, R. N., and Loyola-Vargas, V. M. (2015). The role of chromatin modifications in somatic embryogenesis in plants. Front. Plant Sci. 6:635. doi: 10.3389/fpls.2015. 00635

Domzalska, L., Kedracka-Krok, S., Jankowska, U., Grzyb, M., Sobczak, M., Rybczynski, J. J., et al. (2017). Proteomic analysis of stipe explants reveals differentially expressed proteins involved in early direct somatic embryogenesis of the tree fern Cyathea delgadii Sternb. Plant Sci. 258, 61-76. doi: 10.1016/j. plantsci.2017.01.017

dos Santos, A. L. W., Elbl, P., Navarro, B. V., de Oliveira, L. F., Salvato, F., Balbuena, T. S., et al. (2016). Quantitative proteomic analysis of Araucaria angustifolia (Bertol.) Kuntze cell lines with contrasting embryogenic potential. J. Proteom. 130, 180-189. doi: 10.1016/j.jprot.2015.09.027

Dunkley, T. P., Watson, R., Griffin, J. L., Dupree, P., and Lilley, K. S. (2004). Localization of organelle proteins by isotope tagging (LOPIT). Mol. Cell. Prot. 3, 1128-1134. doi: 10.1074/mcp.T400009-MCP200

Ellis, R. J., and Van der Vies, S. M. (1991). Molecular chaperones. Annu. Rev. Biochem. 60, 321-347. doi: 10.1146/annurev.bi.60.070191.001541 
Engelsberger, W. R., Erban, A., Kopka, J., and Schulze, W. X. (2006). Metabolic labeling of plant cell cultures with $\mathrm{K} 15 \mathrm{NO} 3$ as a tool for quantitative analysis of proteins and metabolites. Plant Methods 2:14. doi: 10.1186/1746-4811-2-14

Fehér, A. (2015). Somatic embryogenesis - Stress-induced remodeling of plant cell fate. Biochim. Biophys. Acta 1849, 385-402. doi: 10.1016/j.bbagrm.2014.07.005

Fraga, H. P. F., Vieira, L. N., Heringer, A. S., Puttkammer, C. C., Silveira, V., and Guerra, M. P. (2016). DNA methylation and proteome profiles of Araucaria angustifolia (Bertol.) Kuntze embryogenic cultures as affected by plant growth regulators supplementation. Plant Cell Tissue Org. 125, 353-374. doi: 10.1007/ s11240-016-0956-y

Ge, F., Hu, H., Huang, X., Zhang, Y., Wang, Y., Li, Z., et al. (2017). Metabolomic and proteomic analysis of maize embryonic callus induced from immature embryo. Sci. Rep. 7:1004. doi: 10.1038/s41598-017-01280-8

Ge, X., Zhang, C., Wang, Q., Yang, Z., Wang, Y., Zhang, X., et al. (2014). iTRAQ protein profile differential analysis between somatic globular and cotyledonary embryos reveals stress, hormone, and respiration involved in increasing plantlet regeneration of Gossypium hirsutum L. J. Proteome Res. 14, 268-278. doi: 10. $1021 / \mathrm{pr} 500688 \mathrm{~g}$

Gómez, A., López, J. A., Pintos, B., Camafeita, E., and Bueno, M. Á (2009). Proteomic analysis from haploid and diploid embryos of Quercus suber L. identifies qualitative and quantitative differential expression patterns. Proteomics 9, 4355-4367. doi: 10.1002/pmic.200900179

Gomez-Garay, A., Lopez, J. A., Camafeita, E., Bueno, M. A., and Pintos, B. (2013). Proteomic perspective of Quercus suber somatic embryogenesis. J. Proteom. 93, 314-325. doi: 10.1016/j.jprot.2013.06.006

Guzmán-García, E., Sánchez-Romero, C., Panis, B., and Carppentier, S. C. (2013). The use of 2D-DIGE to understand the regeneration of somatic embryos in avocado. Proteomics 13, 3498-3507. doi: 10.1002/pmic.201300148

Halliwell, B. (2006). Reactive species and antioxidants. Redox biology is a fundamental theme of aerobic life. Plant Physiol. 141, 312-322. doi: 10.1104/ pp.106.077073

Hanania, U., Velcheva, M., Sahar, N., Flaishman, M., Or, E., Dgani, O., et al. (2009). Suppression and overexpression of ubiquitin extension protein S27a affects cell proliferation and in vitro regeneration in Nicotiana benthamiana. Plant Sci. 176, 566-574. doi: 10.1016/j.plantsci.2009.01.019

Hebeler, R., Oeljeklaus, S., Reidegeld, K. A., Eisenacher, M., Stephan, C., Sitek, B., et al. (2008). Study of early leaf senescence in Arabidopsis thaliana by quantitative proteomics using reciprocal $14 \mathrm{~N} / 15 \mathrm{~N}$ labeling and difference gel electrophoresis. Mol. Cell. Prot. 7, 108-120. doi: 10.1074/mcp.M700340MCP200

Heringer, A. S., Barroso, T., Macedo, A. F., Santa-Catarina, C., Souza, G. H. M. F., Floh, E. I. S., et al. (2015). Label-free quantitative proteomics of embryogenic and non-embryogenic callus during sugarcane somatic embryogenesis. PLoS One 10:e0127803. doi: 10.1371/journal.pone.0127803

Heringer, A. S., Reis, R. S., Passamani, L. Z., de Souza-Filho, G. A., SantaCatarina, C., and Silveira, V. (2017). Comparative proteomics analysis of the effect of combined red and blue lights on sugarcane somatic embryogenesis. Acta Physiol. Plant. 39:52. doi: 10.1007/s11738-017-2349-1

Huttlin, E. L., Hegeman, A. D., Harms, A. C., and Sussman, M. R. (2007). Comparison of full versus partial metabolic labeling for quantitative proteomics analysis in Arabidopsis thaliana. Mol. Cell. Prot. 6, 860-881. doi: 10.1074/mcp. M600347-MCP200

Imin, N., Nizamidin, M., Daniher, D., Nolan, K. E., Rose, R. J., and Rolfe, B. G. (2005). Proteomic analysis of somatic embryogenesis in Medicago truncatula. Explant cultures grown under 6-benzylaminopurine and 1-naphthaleneacetic acid treatments. Plant Physiol. 137, 1250-1260. doi: 10.1104/pp.104.055277

Indoliya, Y., Tiwari, P., Chauhan, A. S., Goel, R., Shri, M., Bag, S. K., et al. (2016). Decoding regulatory landscape of somatic embryogenesis reveals differential regulatory networks between japonica and indica rice subspecies. Sci. Rep. 6:23050. doi: 10.1038/srep23050

Ippel, J. H., Pouvreau, L., Kroef, T., Gruppen, H., Versteeg, G., van den Putten, P., et al. (2004). In vivo uniform $15 \mathrm{~N}$-isotope labelling of plants: using the greenhouse for structural proteomics. Proteomics 4, 226-234. doi: 10.1002/ pmic.200300506

Jamaluddin, N. D., Mohd Noor, N., and Goh, H. H. (2017). Genome-wide transcriptome profiling of Carica papaya L. embryogenic callus. Physiol. Mol. Biol. Plants 23, 357-368. doi: 10.1007/s12298-017-0429-8
Jasmina, K., Li, Y., and Smalle, J. (2013). Proteasome-dependent proteolysis has a critical role in fine-tuning the feedback inhibition of cytokinin signaling. Plant Signal. Behav. 8:e23474. doi: 10.4161/psb.23474

Jin, F., Hu, L., Yuan, D., Xu, J., Gao, W., He, L., et al. (2014). Comparative transcriptome analysis between somatic embryos (SEs) and zygotic embryos in cotton: evidence for stress response functions in SE development. Plant Biotechnol. J. 12, 161-173. doi: 10.1111/pbi.12123

Jing, D., Zhang, J., Xia, Y., Kong, L., OuYang, F., Zhang, S., et al. (2017). Proteomic analysis of stress-related proteins and metabolic pathways in Picea asperata somatic embryos during partial desiccation. Plant Biotechnol. J. 15, 27-38. doi: 10.1111/pbi.12588

Jo, L., Dos Santos, A. L. W., Bueno, C. A., Barbosa, H. R., and Floh, E. I. S. (2014). Proteomic analysis and polyamines, ethylene and reactive oxygen species levels of Araucaria angustifolia (Brazilian pine) embryogenic cultures with different embryogenic potential. Tree Physiol. 34, 94-104. doi: 10.1093/treephys/ tpt102

Kelley, D. (2018). E3 ubiquitin ligases: key regulators of hormone signaling in plants. Mol. Cell. Prot. 17, 1047-1054. doi: 10.1074/mcp.MR117.000476

Kim, D. Y., Scalf, M., Smith, L. M., and Vierstra, R. D. (2013). Advanced proteomic analyses yield a deep catalog of ubiquitylation targets in Arabidopsis. Plant Cell 25, 1523-1540. doi: $10.1105 /$ tpc.112.108613

Kim, J. K., Harada, K., Bamba, T., Fukusaki, E., and Kobayashi, A. (2005), Stable isotope dilution-based accurate comparative quantification of nitrogencontaining metabolites in Arabidopsis thaliana T87 cells using in vivo $15 \mathrm{~N}$ isotope enrichment. Biosci. Biotechnol. Biochem. 69, 1331-1340. doi: 10.1271/ bbb.69.1331

Kleffmann, T., Russenberger, D., von Zychlinski, A., Christopher, W., Sjölander, K., Gruissem, W., et al. (2004). The Arabidopsis thaliana chloroplast proteome reveals pathway abundance and novel protein functions. Curr. Biol. 14, 354362. doi: 10.1016/j.cub.2004.02.039

Klubicová, K., Uvácková, L., Danchenko, M., Nemecek, P., Skultéty, L., Salaj, J., et al. (2017). Insights into the early stage of Pinus nigra Arn. somatic embryogenesis using discovery proteomics. J. Proteom. 169, 99-111. doi: 10. 1016/j.jprot.2017.05.013

Kumaravel, M., Uma, S., Backiyarani, S., Saraswathi, M. S., Vaganan, M. M., Muthusamy, M., et al. (2017). Differential proteome analysis during early somatic embryogenesis in Musa spp. AAA cv. Grand Naine. Plant Cell Rep. 36, 163-178. doi: 10.1007/s00299-016-2067-y

Laganowsky, A., Gómez, S. M., Whitelegge, J. P., and Nishio, J. N. (2009). Hydroponics on a chip: analysis of the Fe deficient Arabidopsis thylakoid membrane proteome. J. Proteom. 72, 397-415. doi: 10.1016/j.jprot.2009.01.024

Lanquar, V., Kuhn, L., Lelièvre, F., Khafif, M., Espagne, C., Bruley, C., et al. (2007). 15N-metabolic labeling for comparative plasma membrane proteomics in Arabidopsis cells. Proteomics 7, 750-754. doi: 10.1002/pmic.200600791

Lavy, M., and Estelle, M. (2016). Mechanisms of auxin signaling. Development 143, 3226-3229. doi: 10.1242/dev.131870

Lee, D. S., Kim, B. K., Kwon, S. J., Jin, H. C., and Park, O. K. (2009). Arabidopsis GDSL lipase 2 plays a role in pathogen defense via negative regulation of auxin signaling. Biochem. Biophys. Res. Commun. 379, 1038-1042. doi: 10.1016/j.bbrc. 2009.01.006

Li, Q., Zhang, S., and Wang, J. (2015). Transcriptomic and proteomic analyses of embryogenic tissues in Picea balfouriana treated with 6-benzylaminopurine. Physiol. Plant. 154, 95-113. doi: 10.1111/ppl.12276

Li-Beisson, Y., Shorrosh, B., Beisson, F., Andersson, M. X., Arondel, V., Bates, P. D., et al. (2013). Acyl-lipid metabolism. Arabidopsis Book 11:e0161. doi: $10.1199 /$ tab.0161

Lippert, D., Zhuang, J., Ralph, S., Ellis, D. E., Gilbert, M., Olafson, R., et al. (2005). Proteome analysis of early somatic embryogenesis in Picea glauca. Proteomics 5, 461-473. doi: 10.1002/pmic.200400986

Liu, C.-P., Yang, L., and Shen, H.-L. (2015). Proteomic analysis of immature Fraxinus mandshurica cotyledon tissues during somatic embryogenesis: effects of explant browning on somatic embryogenesis. Int. J. Mol. Sci. 16, 1369213713. doi: $10.3390 / \mathrm{ijms} 160613692$

Loyola-Vargas, V. M., and Ochoa-Alejo, N. (2016). "Somatic embryogenesis. An overview," in Somatic Embryogenesis. Fundamental Aspects and Applications, eds V. M. Loyola-Vargas and N. Ochoa-Alejo (Berlin: Springer), 1-10. doi: 10.1007/978-3-319-33705-0 
Luethy, M. H., Gemel, J., Johnston, M. L., Mooney, B. P., Miernyk, J. A., and Randall, D. D. (2001). Developmental expression of the mitochondrial pyruvate dehydrogenase complex in pea (Pisum sativum) seedlings. Physiol. Plant. 112, 559-566. doi: 10.1034/j.1399-3054.2001.1120414.x

Lyngved, R., Renaut, J., Hausman, J. F., Iversen, T. H., and Hvoslef-Eide, A. K. (2008). Embryo-specific proteins in Cyclamen persicum analyzed with 2-D DIGE. J. Plant Growth Regul. 27, 353-369. doi: 10.1007/s00344-008-9061-8

Magnani, E., Jiménez-Gómez, J. M., Soubigou-Taconnat, L., Lepiniec, L., and Fiume, E. (2017). Profiling the onset of somatic embryogenesis in Arabidopsis. BMC Genomics 18:998. doi: 10.1186/s12864-017-4391-1

Márquez-López, R. E., Pérez-Hernández, C. A., Kú-González, Á, Galaz-Ávalos, R. M., and Loyola-Vargas, V. M. (2018). Localization and transport of indole3 -acetic acid during somatic embryogenesis in Coffea canephora. Protoplasma 255, 695-708. doi: 10.1007/s00709-017-1181-1

Marshall, R. S., and Vierstra, R. D. (2018). Autophagy: the master of bulk and selective recycling. Annu. Rev. Plant Biol. 69, 173-208. doi: 10.1146/annurevarplant-042817-040606

Marsoni, M., Bracale, M., Espen, L., Prinsi, B., Negri, A., and Vannini, C. (2008). Proteomic analysis of somatic embryogenesis in Vitis vinifera. Plant Cell Rep. 27, 347-356. doi: 10.1007/s00299-007-0438-0

Mason, M. G., Mathews, D. E., Argyros, D. A., Maxwell, B. B., Kieber, J. J., Alonso, J. M., et al. (2005). Multiple type-B response regulators mediate cytokinin signal transduction in Arabidopsis. Plant Cell 17, 3007-3018. doi: 10.1105/tpc.105. 035451

Morel, A., Teyssier, C., Trontin, J. F., Eliasová, K., Pesek, B., Beaufour, M., et al. (2014a). Early molecular events involved in Pinus pinaster Ait. somatic embryo development under reduced water availability: transcriptomic and proteomic analyses. Physiol. Plant. 152, 184-201. doi: 10.1111/ppl. 12158

Morel, A., Trontin, J. F., Corbineau, F., Lomenech, A. M., Beaufour, M., Reymond, I., et al. (2014b). Cotyledonary somatic embryos of Pinus pinaster Ait. most closely resemble fresh, maturing cotyledonary zygotic embryos: biological, carbohydrate and proteomic analyses. Planta 240, 1075-1095. doi: 10.1007/s00425-0142125-Z

Mou, Z. L., He, Y. K., Dai, Y., Liu, X. F., and Li, J. Y. (2000). Deficiency in fatty acid synthase leads to premature cell death and dramatic alterations in plant morphology. Plant Cell 12, 405-417. doi: 10.1105/tpc.12.3.405

Mwangi, J. W., Rode, C., Colditz, F., Haase, C., Braun, H. P., and Winkelmann, T. (2013). Proteomic and histological analyses of endosperm development in Cyclamen persicum as a basis for optimization of somatic embryogenesis. Plant Sci. 20, 52-65. doi: 10.1016/j.plantsci.2012.11.004

Neff, M. M., Nguyen, S. M., Malancharuvil, E. J., Fujioka, S., Noguchi, T., Seto, H., et al. (1999). BAS1: a gene regulating brassinosteroid levels and light responsiveness in Arabidopsis. Proc. Natl. Acad. Sci. U.S.A. 96, 15316-15323. doi: $10.1073 /$ pnas.96.26.15316

Nelson, C. J., Huttlin, E. L., Hegeman, A. D., Harms, A. C., and Sussman, M. R. (2007). Implications of $15 \mathrm{~N}$-metabolic labeling for automated peptide identification in Arabidopsis thaliana. Proteomics 7, 1279-1292. doi: 10.1002/ pmic. 200600832

Niemenak, N., Kaiser, E., Maximova, S. N., Laremore, T., and Guiltinan, M. J. (2015). Proteome analysis during pod, zygotic and somatic embryo maturation of Theobroma cacao. J. Plant Physiol. 180, 49-60. doi: 10.1016/j.jplph.2015. 02.011

Niu, L., Yuan, H., Gong, F., Wu, X., and Wang, W. (2018). Protein extraction methods shape much of the extracted proteomes. Front. Plant Sci. 9:802. doi: 10.3389/fpls.2018.00802

Noah, A. M., Niemenak, N., Sunderhaus, S., Haase, C., Omokolo, D. N., Winkelmann, T., et al. (2013). Comparative proteomic analysis of early somatic and zygotic embryogenesis in Theobroma cacao L. J. Proteom. 78, 123-133. doi: 10.1016/j.jprot.2012.11.007

Nogueira, F., Goncalves, E., Jereissati, E., Santos, M., Costa, J., Oliveira-Neto, O., et al. (2007). Proteome analysis of embryogenic cell suspensions of cowpea (Vigna unguiculata). Plant Cell Rep. 26, 1333-1343. doi: 10.1007/s00299-0070327-6

Olinares, P. D., Ponnala, L., and van Wijk, K. J. (2010). Megadalton complexes in the chloroplast stroma of Arabidopsis thaliana characterized by size exclusion chromatography, mass spectrometry and hierarchical clustering. Mol. Cell. Prot. 9, 1594-1615. doi: 10.1074/mcp.M000038-MCP201

Pan, Z., Guan, R., Zhu, S., and Deng, X. (2009). Proteomic analysis of somatic embryogenesis in Valencia sweet orange (Citrus sinensis Osbeck). Plant Cell Rep. 28, 281-289. doi: 10.1007/s00299-008-0633-7

Pan, Z., Zhu, S., Guan, R., and Deng, X. (2010). Identification of 2,4-D-responsive proteins in embryogenic callus of Valencia sweet orange (Citrus sinensis Osbeck) following osmotic stress. Plant Cell Tissue Org. 103, 145-153. doi: 10.1007/s11240-010-9762-0

Peltier, J.-B., Ripoll, D. R., Friso, G., Rudella, A., Cai, Y., Ytterberg, J., et al. (2004). Clp protease complexes from photosynthetic and non-photosynthetic plastids and mitochondria of plants, their predicted three-dimensional structures, and functional implications. J. Biol. Chem. 279, 4768-4781. doi: 10.1074/jbc. M309212200

Pidkowich, M. S., Nguyen, H. T., Heilmann, I., Ischebeck, T., and Shanklin, J. (2007). Modulating seed $\beta$-ketoacyl-acyl carrier protein synthase II level converts the composition of a temperate seed oil to that of a palm-like tropical oil. Proc. Natl. Acad. Sci. U.S.A. 104, 4742-4747. doi: 10.1073/pnas.0611141104

Pila Quinga, L. A., Heringer, A. S., Pacheco, de Freitas Fraga, H., do Nascimento, Vieira, L., et al. (2018). Insights into the conversion potential of Theobroma cacao L. somatic embryos using quantitative proteomic analysis. Sci. Hortic. 229, 65-76. doi: 10.1016/j.scienta.2017.10.005

Quiroz-Figueroa, F. R., Méndez-Zeel, M., Sánchez-Teyer, F., Rojas-Herrera, R., and Loyola-Vargas, V. M. (2002). Differential gene expression in embryogenic and non-embryogenic clusters from cell suspension cultures of Coffea arabica $\mathrm{L}$. J. Plant Physiol. 159, 1267-1270. doi: 10.1078/0176-1617-00878

Ravanel, S., Gakière, B., Job, D., and Douce, R. (1998). The specific features of methionine biosynthesis and metabolism in plants. Proc. Natl. Acad. Sci. U.S.A. 95, 7805-7812. doi: 10.1073/pnas.95.13.7805

Reis, R. S., Vale, E. D. M., Heringer, A. S., Santa-Catarina, C., and Silveira, V. (2016). Putrescine induces somatic embryo development and proteomic changes in embryogenic callus of sugarcane. J. Proteom. 130, 170-179. doi: 10.1016/j.jprot. 2015.09.029

Rode, C., Gallien, S., Heintz, D., Van Dorsselaer, A., Braun, H. P., and Winkelmann, T. (2011). Enolases: storage compounds in seeds? Evidence from a proteomic comparison of zygotic and somatic embryos of Cyclamen persicum Mill. Plant Mol. Biol. 75, 305-319. doi: 10.1007/s11103-010-9729-x

Rode, C., Lindhorst, K., Braun, H. P., and Winkelmann, T. (2012). From callus to embryo: a proteomic view on the development and maturation of somatic embryos in Cyclamen persicum. Planta 235, 995-1011. doi: 10.1007/s00425011-1554-1

Romano, P. G., Horton, P., and Gray, J. E. (2004). The Arabidopsis cyclophilin gene family. Plant Physiol. 134, 1268-1282. doi: 10.1104/pp.103.022160

Saracco, S. A., Miller, M. J., Kurepa, J., and Vierstra, R. D. (2007). Genetic analysis of SUMOylation in Arabidopsis: conjugation of SUMO1 and SUMO2 to nuclear proteins is essential. Plant Physiol. 145, 119-134. doi: 10.1104/pp.107.102285

Schaff, J. E., Mbeunkui, F., Blackburn, K., Bird, D. M., and Goshe, M. B. (2008). SILIP: a novel stable isotope labeling method for in planta quantitative proteomic analysis. Plant J. 56, 840-854. doi: 10.1111/j.1365-313X.2008. 03639.x

Sghaier-Hammami, B., Drira, N., and Jorrín-Novo, J. V. (2009). Comparative 2DE proteomic analysis of date palm (Phoenix dactylifera L.) somatic and zygotic embryos. J. Proteom. 73, 161-177. doi: 10.1016/j.jprot.2009.07.003

Sghaier-Hammami, B., Jorrín-Novo, J. V., Gargouri-Bouzid, R., and Drira, N. (2010). Abscisic acid and sucrose increase the protein content in date palm somatic embryos, causing changes in 2-DE profile. Phytochemistry 71, 12231236. doi: 10.1016/j.phytochem.2010.05.005

Sharifi, G., Ebrahimzadeh, H., Ghareyazie, B., Gharechahi, J., and Vatankhah, E. (2012). Identification of differentially accumulated proteins associated with embryogenic and non-embryogenic calli in saffron (Crocus sativus L.). Proteome Sci. 10:3. doi: 10.1186/1477-5956-10-3

Sikorskaite, S., Rajamäki, M. L., Baniulis, D., Stanys, V., and Valkonen, J. P. (2013). Protocol: optimised methodology for isolation of nuclei from leaves of species in the Solanaceae and Rosaceae families. Plant Methods 9:31. doi: 10.1186/17464811-9-31

Silva, R. D. C., Carmo, L. S., Luis, Z. G., Silva, L. P., Scherwinski-Pereira, J. E., and Mehta, A. (2014). Proteomic identification of differentially expressed proteins 
during the acquisition of somatic embryogenesis in oil palm (Elaeis guineensis Jacq.). J. Proteom. 104, 112-127. doi: 10.1016/j.jprot.2014.03.013

Smalle, J., Kurepa, J., Yang, P., Babiychuk, E., Kushnir, S., Durski, A., et al. (2002). Cytokinin growth responses in Arabidopsis involve the $26 \mathrm{~S}$ proteasome subunit RPN12. Plant Cell 14, 17-32. doi: 10.1105/tpc.010381

Stanislas, T., Bouyssie, D., Rossignol, M., Vesa, S., Fromentin, J., Morel, J., et al. (2009). Quantitative proteomics reveals a dynamic association of proteins to detergent-resistant membranes upon elicitor signaling in tobacco. Mol. Cell. Prot. 8, 2186-2198. doi: 10.1074/mcp.M900090-MCP200

Sugimoto, K., Gordon, S. P., and Meyerowitz, E. M. (2011). Regeneration in plants and animals: dedifferentiation, transdifferentiation, or just differentiation? Trends Cell Biol. 21, 212-218. doi: 10.1016/j.tcb.2010.12.004

Sun, L., Wu, Y., Zou, H., Su, S., Li, S., Shan, X., et al. (2013). Comparative proteomic analysis of the $\mathrm{H} 99$ inbred maize (Zea mays L.) line in embryogenic and nonembryogenic callus during somatic embryogenesis. Plant Cell Tissue Org. 113, 103-119. doi: 10.1007/s11240-012-0255-1

Teyssier, C., Grondin, C., Bonhomme, L., Lomenech, A. M., Vallance, M., Morabito, D., et al. (2011). Increased gelling agent concentration promotes somatic embryo maturation in hybrid larch (Larix $x$ eurolepsis): a 2-DE proteomic analysis. Physiol. Plant. 141, 152-165. doi: 10.1111/j.1399-3054.2010. 01423.x

Teyssier, C., Maury, S., Beaufour, M., Grondin, C., Delaunay, A., Le Metté, C., et al. (2014). In search of markers for somatic embryo maturation in hybrid larch (Larix $x$ eurolepis): global DNA methylation and proteomic analyses. Physiol. Plant. 150, 271-291. doi: 10.1111/ppl.12081

Thingholm, T. E., Jørgensen, T. J., Jensen, O. N., and Larsen, M. R. (2006). Highly selective enrichment of phosphorylated peptides using titanium dioxide. Nat. Prot. 1, 1929-1935. doi: 10.1038/nprot.2006.185

Tonietto, Â, Hiromi Sato, J., Batista Teixeira, J., de Souza, E. M., Pedrosa, F. O., Franco, O. L., et al. (2012). Proteomic analysis of developing somatic embryos of Coffea arabica. Plant Mol. Biol. Rep. 30, 1393-1399. doi: 10.1007/s11105-0120425-7

Tovar-Méndez, A., Miernyk, J. A., and Randall, D. D. (2003). Regulation of pyruvate dehydrogenase complex activity in plant cells. Eur. J. Biochem. 270, 1043-1049. doi: 10.1046/j.1432-1033.2003.03469.x

Turner, J. G., Ellis, C., and Devoto, A. (2002). The jasmonate signal pathway. Plant Cell 14, S153-S164. doi: 10.1105/tpc.000679

Vale, E. D. M., Heringer, A. S., Barroso, T., Ferreira, A. T., da Costa, M. N., Perales, J. E. A., et al. (2014). Comparative proteomic analysis of somatic embryo maturation in Carica papaya L. Proteome Sci. 12:37. doi: 10.1186/1477-5956$12-37$

Varhaníková, M., Uvackova, L., Skultety, L., Pretova, A., Obert, B., and Hajduch, M. (2014). Comparative quantitative proteomic analysis of embryogenic and nonembryogenic calli in maize suggests the role of oxylipins in plant totipotency. J. Proteom. 104, 57-65. doi: 10.1016/j.jprot.2014.02.003

Vierstra, R. D. (2009). The ubiquitin-26S proteasome system at the nexus of plant biology. Nat. Rev. Mol. Cell Biol. 10, 385-397. doi: 10.1038/nrm2688

Werck-Reichhart, D., Bak, S., and Paquette, S. (2002). Cytochromes P450. Arabidopsis Book 1:e0028. doi: 10.1199/tab.0028

White, S. W., Zheng, J., Zhang, Y. M., and Rock, C. O. (2005). The structural biology of type II fatty acid biosynthesis. Annu. Rev. Biochem. 74, 791-831. doi: 10.1146/annurev.biochem.74.082803.133524

Winkelmann, T., Heintz, D., Van Dorsselaer, A., Serek, M., and Braun, H. P. (2006). Proteomic analyses of somatic and zygotic embryos of Cyclamen persicum Mill. reveal new insights into seed and germination physiology. Planta 224, 508-519. doi: $10.1007 / \mathrm{s} 00425-006-0238-8$
Wirtz, K. W. A. (1991). Phospholipid transfer proteins. Annu. Rev. Biochem. 60, 73-99. doi: 10.1146/annurev.bi.60.070191.000445

Wurtele, E. S., and Nikolau, B. J. (1992). Differential accumulation of biotin enzymes during carrot somatic embryogenesis. Plant Physiol. 99, 1699-1703. doi: 10.1104/pp.99.4.1699

Xia, Y., Jing, D., Kong, L., Zhang, J., OuYang, F., Zhang, H., et al. (2016). Global lysine acetylome analysis of desiccated somatic embryos of Picea asperata. Front. Plant Sci. 7:1927. doi: 10.3389/fpls.2016.01927

Yang, X., and Zhang, X. (2010). Regulation of somatic embryogenesis in higher plants. Crit. Rev. Plant Sci. 29, 36-57. doi: 10.1080/07352680903436291

Yang, X., Zhang, X., Yuan, D., Jin, F., Zhang, Y., and Xu, J. (2012). Transcript profiling reveals complex auxin signalling pathway and transcription regulation involved in dedifferentiation and redifferentiation during somatic embryogenesis in cotton. BMC Plant Biol. 12:110. doi: 10.1186/1471-2229$12-110$

Yin, L., Tao, Y., Zhao, K., Shao, J., Li, X., Liu, G., et al. (2007). Proteomic and transcriptomic analysis of rice mature seed-derived callus differentiation. Proteomics 7, 755-768. doi: 10.1002/pmic.200600611

Zhang, J., Ma, H., Chen, S., Ji, M., Perl, A., Kovacs, L., et al. (2009). Stress response proteins' differential expression in embryogenic and non-embryogenic callus of Vitis vinifera L. cv. Cabernet Sauvignon- A proteomic approach. Plant Sci. 177, 103-113. doi: 10.1016/j.plantsci.2009.04.003

Zhao, J., Li, H., Fu, S., Chen, B., Sun, W., Zhang, J., et al. (2015a). An iTRAQ-based proteomics approach to clarify the molecular physiology of somatic embryo development in Prince Rupprecht's larch (Larix principis-rupprechtii Mayr). PLoS One 10:e0119987. doi: 10.1371/journal.pone.0119987

Zhao, J., Wang, B., Wang, X., Zhang, Y., Dong, M., and Zhang, J. (2015b). iTRAQbased comparative proteomic analysis of embryogenic and non-embryogenic tissues of Prince Rupprecht's larch (Larix principis-rupprechtii Mayr). Plant Cell Tissue Org. 120, 655-669. doi: 10.1007/s11240-014-0633-y

Zhao, Y. (2012). Auxin biosynthesis: a simple two-step pathway converts tryptophan to indole-3-acetic acid in plants. Mol. Plant 5, 334-338. doi: 10. 1093/mp/ssr104

Zhao, Y., Christensen, S. K., Fankhauser, C., Cashmann, J. R., Cohen, J. D., Weigel, D., et al. (2001). A role for flavin monooxygenase-like enzymes in auxin biosynthesis. Science 291, 306-309. doi: 10.1126/science.291.55 02.306

Zhou, T., Yang, X., Guo, K., Deng, J., Xu, J., Gao, W., et al. (2016). ROS homeostasis regulates somatic embryogenesis via the regulation of auxin signaling in cotton. Mol. Cell. Prot. 15, 2108-2124. doi: 10.1074/mcp.M115.049338

Zhu, H. G., Cheng, W. H., Tian, W. G., Li, Y. J., Liu, F., Xue, F., et al. (2018). iTRAQ-based comparative proteomic analysis provides insights into somatic embryogenesis in Gossypium hirsutum L. Plant Mol. Biol. 96, 89-102. doi: 10.1007/s11103-017-0681-x

Conflict of Interest Statement: The authors declare that the research was conducted in the absence of any commercial or financial relationships that could be construed as a potential conflict of interest.

Copyright (®) 2018 Aguilar-Hernández and Loyola-Vargas. This is an open-access article distributed under the terms of the Creative Commons Attribution License (CC BY). The use, distribution or reproduction in other forums is permitted, provided the original author(s) and the copyright owner(s) are credited and that the original publication in this journal is cited, in accordance with accepted academic practice. No use, distribution or reproduction is permitted which does not comply with these terms. 